\title{
Article \\ Benchmarking Newer Multiaxial Fatigue Strength Criteria on Data Sets of Various Sizes
}

\author{
Jan Papuga ${ }^{1, *(\mathbb{D}}$, Martin Nesládek ${ }^{1}$, Alexander Hasse ${ }^{2}$, Eva Cízová ${ }^{1}$ and Lukáš Suchý ${ }^{2}(\mathbb{C}$ \\ 1 Faculty of Mechanical Engineering, Czech Technical University in Prague, Technická 4, \\ 16607 Prague, Czech Republic; martin.nesladek@fs.cvut.cz (M.N.); evacizova@centrum.cz (E.C.) \\ 2 Institute of Design Engineering and Drive Technology, Technische Universität Chemnitz, \\ 09126 Chemnitz, Germany; alexander.hasse@mb.tu-chemnitz.de (A.H.); \\ lukas.suchy@mb.tu-chemnitz.de (L.S.) \\ * Correspondence: jan.papuga@fs.cvut.cz; Tel.: +420-737-977-741
}

Citation: Papuga, J.; Nesládek, M.; Hasse, A.; Cízová, E.; Suchý, L. Benchmarking Newer Multiaxial Fatigue Strength Criteria on Data Sets of Various Sizes. Metals 2022, 12, 289. https: / / doi.org/10.3390/ met12020289

Academic Editors: Denis Benasciutti and Luis Reis

Received: 31 December 2021

Accepted: 4 February 2022

Published: 7 February 2022

Publisher's Note: MDPI stays neutral with regard to jurisdictional claims in published maps and institutional affiliations.

Copyright: (C) 2022 by the authors. Licensee MDPI, Basel, Switzerland. This article is an open access article distributed under the terms and conditions of the Creative Commons Attribution (CC BY) license (https:// creativecommons.org/licenses/by/ $4.0 /)$.

\begin{abstract}
The paper presents a comparison of six recently introduced multiaxial fatigue strength estimation criteria to four methods, the large-scope validation of which has already been published. The results obtained for each newer method are analyzed and discussed. From the newer methods, only the criterion by Böhme reaches an estimation quality similar to the best performing criteria. The validation was performed on the FatLim data sets, but the primary focus of the paper is set to analyzing the validation on a smaller AMSD25 data set derived from it. The comparison shows that the application of AMSD25 for validation practice allows users to reduce the number of evaluated test cases, while generally preserving the worst cases showing the weaknesses of various estimation methods.
\end{abstract}

Keywords: multiaxial fatigue; high-cycle fatigue; mean stress effect; AMSD25 benchmark

\section{Introduction}

One of the most famous early multiaxial fatigue strength solutions was proposed by Gough and Pollard on the basis of their extensive experimental effort [1-3]. It was derived in [1] for the input of nominal shear stress $\tau_{x y a}$ and axial stress $\sigma_{x a}$ amplitudes, which corresponded to the experimental combination the authors were able to impose on the tested samples.

The concept of the testing machine allowed the researchers to modify the mutual ratio between acting bending moment and torque, but it did not allow them to check the effect of the out-of-phase loading, or to involve any additional load channel. In the discussion of their findings in [1], the idea of the critical plane, which could be responsible for the damage level of the whole sample, was raised by Stanfield. This idea was successfully implemented by Findley [4] in the first multiaxial fatigue strength criterion of the critical plane type. Findley also focused in his experiments [5] on load combinations of bending and torsion without any phase shift between them (this time at least significant mean stresses were induced), but the concept of the critical plane allowed the criterion to process also more complicated stress states.

The experimental effort went beyond that border in next years, and soon the concept of pressurized hollow samples allowed experimenters to implement the further acting stress in the hoop direction of the pressurized hollow sample (e.g., Rotvel [6]) or to induce a phase shift between acting load channels (e.g., Mielke [7]). Once the hoop stress came into play, the original Gough and Pollard criterion lost its significance because it was not formulated to take such an input into account. Findings that the response of material under out-of-phase loading is not identical to the response to in-phase loading with individual stress amplitudes of the same magnitude (explicated, e.g., by Fatemi and Socie [8]) were another driving force to replace this type of the criterion independent of the phase shift by 
newer solutions. Several concepts emerged in addition to the critical plane solution first proposed by Findley:

1. The original critical plane solution split into two main branches differing in the parameter which is found maximum to mark the plane as the critical one:

a. The entire equivalent stress derived from stresses on each evaluated plane $[4,9,10]$; b. The maximum shear stress range found on any evaluated plane [11-13].

2. Integral criteria, which integrate either the equivalent stress or individual stress components over all potential orientations of planes in the evaluated point [14-17];

3. Invariant criteria, often based on an evaluation of the second invariant of the stress tensor deviator and of the first invariant of the stress tensor [18-20].

The boom of inventing new multiaxial fatigue strength criteria started in the 1990s up to the point, which Stefanov described: "It is fairly traditional that each author develops his own criterion for fatigue life prediction and verifies it by his own experimental data. Then some other author's data are not satisfied by that criterion, and a new one is suggested. Thus too many proposed criteria have been accumulated ... Many criteria have remained isolated each from other, without comparison or competition." ([21], p. 42). The first decade of the 21st century saw some attempts in limiting this abundance by increasing the scope of used data sets of experimental data (named benchmark sets hereafter) on which the newly proposed criteria should be validated (Weber [22], Susmel [23], Papuga [24,25]). This phase could be ended by the survey paper by Papuga [26], who compared 18 different criteria on the benchmark set of 407 data items. Be it the heated exchange of opinions between Susmel [27] and Papuga [28] in the response to this article, or simply the attention of fatigue researchers drifted away to focus on less-analyzed fatigue estimation domains, the number of new creations among new multiaxial fatigue criteria decreased significantly after that point.

An extensive comparison of various criteria was presented shortly after by Bruun and Härkegård [29]. Papuga published several versions of his criteria in attempts to highlight the importance of the mean shear stress effect $[10,17,30]$. The paper presented here focuses on new criteria proposed in the literature after 2011, which were not benchmarked in such a profound way because the scope of the data set used for their validation was substantially smaller. Papuga et al. [31] proposed to use the newly established AMSD25 benchmark for this special case, so that the properties of the new criteria could be shown. It comprises 57 items, which are completely described in the paper [31], and which thus can serve as the primary input for any benchmarking analysis. The key ideas used in its definition were to select the test items that provoked the highest variation in results among different evaluated multiaxial fatigue strength criteria, or which were generally leading to bad estimates. In that way, the majority of existing data items often used for benchmarking were abandoned, because the response to them is good enough by most existing multiaxial fatigue strength criteria.

This paper focuses on benchmarking several recently developed multiaxial fatigue strength criteria. Each was validated on another data set, differing both in the number of items and in their selection. The validation in this paper is documented on the AMSD25 benchmark set. To see the difference in the response, the original full-scale FatLim data set [32] used for its definition is also applied. The resulting data are compared and the weak points of the new criteria are highlighted. To gain insight into the quality of new criteria compared to other available multiaxial fatigue strength criteria, four reference criteria are chosen. Three Papuga's criteria are chosen as reference because of their good performance proven in [10,17,30], and the fourth criterion is the Dang Van criterion [33]. It is chosen because it is currently the most widely used solution in industry, as it is implemented as the key solution in most of the fatigue solver packages available on the market [34]. 


\section{Materials and Methods}

\subsection{Used Benchmark Data Sets}

The full FatLim benchmark is currently composed of 284 items. This is a much smaller number than the FatLim referred to in [26], because many stringent criteria were applied to assess the validity of the data accepted in it [32]. The load cases collected can be categorized according to their various aspects into the groups shown in Table 1. This table describes the number of items in the FatLim benchmark in the first position, while the number of items in the reduced AMSD25 data set (published in full in [31]) is behind the slash. It has already been mentioned that the key to the selection of items for the AMSD25 benchmark set was the level of divergence of predictions produced by many different criteria from perfect ones. The "AM" part of the title of the benchmark set refers to the absolute mean. In the analysis, the mean value of the relative prediction error of various criteria on the examined data item was evaluated in its absolute value. "SD" corresponds to the standard deviation of these prediction outputs for each assessed item. When the sum of these two parameters reached a critical value of $25 \%$, the item was selected for the AMSD25 data set.

Table 1. The structure of the whole FatLim benchmark set and of the AMSD25 data set. The number before the slash refers to the number of items of the group in the full FatLim data set, while the number of items in the AMSD25 data set is behind the slash. Abbreviations: Uni-uniaxial loading, MSinvolves mean stresses, MS—involves compressive mean stresses, NP—non-proportional loading, IP-in-phase loading, OOP-out-of-phase loading. The AMSD25/FL ratio depicts how many percent of the original FatLim items remained in AMSD25.

\begin{tabular}{|c|c|c|c|c|c|c|c|c|c|c|}
\hline $\begin{array}{c}\text { Material } \\
\text { Group }\end{array}$ & $\{$ Uni $\}$ & $\{\mathrm{MS}\}$ & $\{$ MS- $\}$ & $\{\mathrm{NP}\}$ & $\{$ IP $\}$ & $\{\mathrm{IP}, \mathrm{nMS}\}$ & $\{\mathrm{OOP}\}$ & $\{\mathrm{OOP}, \mathrm{nMS}\}$ & Total & $\begin{array}{l}\text { AMSD25/ } \\
\text { FL Ratio }\end{array}$ \\
\hline Al-alloys & $25 / 11$ & $42 / 19$ & $0 / 0$ & $9 / 1$ & $24 / 8$ & $13 / 1$ & $5 / 1$ & $3 / 0$ & $58 / 20$ & $34.5 \%$ \\
\hline Cast irons & $8 / 4$ & $14 / 6$ & $5 / 2$ & $8 / 2$ & $11 / 1$ & $10 / 0$ & $8 / 2$ & $3 / 1$ & $27 / 7$ & $25.9 \%$ \\
\hline Cu-alloys & $0 / 0$ & $0 / 0$ & $0 / 0$ & $7 / 0$ & $1 / 0$ & $1 / 0$ & $7 / 0$ & $7 / 0$ & $8 / 0$ & $0.0 \%$ \\
\hline Steels & $26 / 7$ & $140 / 27$ & $35 / 4$ & $99 / 20$ & $66 / 3$ & $35 / 0$ & $54 / 8$ & $16 / 3$ & $191 / 30$ & $15.7 \%$ \\
\hline Total & $59 / 22$ & $196 / 52$ & $40 / 6$ & $123 / 23$ & $102 / 12$ & $59 / 1$ & $74 / 11$ & $29 / 4$ & $284 / 57$ & $20.1 \%$ \\
\hline AMSD25/FL & $37.3 \%$ & $26.5 \%$ & $15.0 \%$ & $18.7 \%$ & $11.8 \%$ & $1.7 \%$ & $14.9 \%$ & $13.8 \%$ & $20.1 \%$ & \\
\hline
\end{tabular}

This approach causes that the AMSD25 data set gathers above all items, for which either too few methods provided good estimates (i.e., AM parameter was high) or the estimates of individual methods were very different (i.e., SD parameter was high). It is obvious in Table 1, that the group of in-phase $\{\mathrm{IP}\}$ loading is reduced to the AMSD25 data set by the factor 9 , and if there are no mean stresses $\{\mathrm{IP}, \mathrm{nMS}\}$ the reduction factor reaches 59. This observation can be interpreted as implying that this kind of loading is successfully simulated by almost any multiaxial fatigue strength criterion. Another interesting aspect is that the same conversion ratio when calculated for other items shows that the biggest issue for the prediction methods is not non-proportional $\{\mathrm{NP}\}$ or out-of-phase loading $\{\mathrm{OOP}\}$, which are the typical focused cases for such methods, but the response to load cases with non-zero mean stresses $\{\mathrm{MS}\}$. This fact also projects to the Uniaxial group, which covers the one-channel load cases, invariably with non-zero mean stress.

Another interesting point in this comparison is the representation of various material types. This shows that the test cases on steels are much better represented by the multiaxial fatigue strength criteria than it can be observed for aluminum alloys or for cast irons, which diffused into the AMSD25 benchmark set in a larger proportion. It can only be speculated on whether this is a material-dependent consequence, or if simply the more often tested steel samples were routinely tested under load cases, which are harmless. The conversion ratio 22 reached for the \{Steels, IP\} group shows that the latter option can be right at least partly. 


\subsection{Evaluated Multixial Fatigue Strength Criteria}

Six new multiaxial fatigue strength criteria were selected for this paper. They are described in the next subsections. In addition to them, four reference criteria are included. PCN (Papuga's Critical plane solution in Newer version) is the latest extension of the original PCr critical plane method published first in [24] and rectified in [26]. It is chosen because of its general good prediction capability [10]. The PIN (Papuga's Integral criterion in Newer version) criterion, which is an extension of the integral PI method [24,26], was published in [17]. It is chosen for the same reason, but also to provide a better partner in comparison to the Böhme criterion, which is also of the integral type. The MMP (Manson-McKnight-Papuga) criterion is included because of its simplicity, allowing the analyst to run the computation within, e.g., MS Excel, while it reaches still sufficient level of prediction quality (see [30,35]). The Dang Van criterion [33] dominates practical engineering solutions, as it is implemented in most fatigue solvers available on the market [34]. Results of these four additional criteria will not be further scrutinized, they are provided here only to show the differences in the response in comparison to the six assessed newer criteria.

\subsubsection{Khalij and Pagnacco (KP) Criterion}

This criterion [36] was created with the interesting idea of extending the applicability of the general Gough-Pollard criterion to more complicated cases that also encompass the general plane stress state, including another normal stress component. The original Gough-Pollard formula combining the axial stress amplitude $\sigma_{x a}$ and the shear stress amplitude $\tau_{x y}$ follows:

$$
\left(\frac{\sigma_{x a}}{s_{-1}}\right)^{2}+\left(\frac{\tau_{x y a}}{t_{-1}}\right)^{2} \leq 1 .
$$

Here, $s_{-1}$ refers to the fatigue strength in fully reversed axial loading, while $t_{-1}$ corresponds to the fatigue strength in fully reversed torsion. Using the fatigue strength ratio $\kappa=s_{-1} / t_{-1}$ as a key material parameter, the criterion can be rewritten as follows:

$$
\sigma_{e q, G P}=\frac{\sigma_{x a}^{2}}{s_{-1}}+\frac{\kappa \tau_{x y a}^{2}}{t_{-1}} \leq s_{-1}
$$

In [2], Gough and Pollard modified the criterion to a more complicated formula:

$$
(\kappa-1)\left(\frac{\sigma_{x a}}{s_{-1}}\right)^{2}+\left(\frac{\tau_{x y a}}{t_{-1}}\right)^{2}+(2-\kappa)\left(\frac{\sigma_{x a}}{s_{-1}}\right) \leq 1,
$$

which was expected to better describe the response of the materials in their experiments.

The general formulation of the KP criterion [36] is based on extending the original axial stress term to a formula, which also encompasses the second possible normal stress $\sigma_{y}$ :

$$
a_{K P} \cdot \frac{\left[\sigma_{x}^{2}+\sigma_{y}^{2}-\sigma_{x} \sigma_{y} \cos \delta_{y y}\right]}{s_{-1}^{2}}+\left(\frac{\tau_{x y}}{t_{-1}}\right)^{2}+\left(1-a_{K P}\right) \frac{\sqrt{\sigma_{x}^{2}+\sigma_{y}^{2}+2 \sigma_{x} \sigma_{y} \cos \delta_{y y}}}{s_{-1}}+b_{K P} \sigma_{m, B}+
$$

There are three material parameters involved $\left(a_{K P}, b_{K P}\right.$, and $\left.c_{K P}\right)$, the phase shift between both normal stresses $\delta_{y y}$ and two stress parameters $\sigma_{m, B}$ and $\sigma_{m, C}$, which are calculated from complicated formulas [36] composed of mean values and amplitudes of all involved stress channels. The two last addends in Equation (4) describing the effect of mean stresses are completely retrieved from the paper by Liu [37]. The lengthy definition of $\sigma_{m, B}$ 
and $\sigma_{m, C}$ is so complicated that the authors of [36] admitted in personal communication that an error was induced in the transcription of two from all parameters, and thus the correct formulation should be found in [37]. Two of the material parameters involved in Equation (4) are:

$$
\begin{aligned}
& b_{K P}=\frac{7}{4} s_{-1}^{2}\left[\left(\frac{2}{t_{0}}\right)^{2}-\left(\frac{1}{t_{-1}}\right)^{2}\right] \\
& c_{K P}=\frac{7}{5}\left[4\left(\frac{s_{-1}}{s_{0}}\right)^{2}-\frac{4 b_{K P}}{21}-1\right]
\end{aligned}
$$

Here, $s_{0}$ refers to the fatigue strength in repeated axial loading (that is, with the load ratio $R=0$ ), and $t_{0}$ refers to the fatigue strength in repeated torsion. The last unknown material parameter in Equation (4) is $a_{K P}$, for which Khalij et al. set three different definitions. The first one, designated OP, is derived by using Equation (4) for the pure torsion load case. The authors expected the independence of Equation (4) on the chosen coordinate system, and thus they evaluated the torsion load case on the plane normal to the principal direction. This analysis reaches then:

$$
a_{K P, O P}=\kappa^{2} / 3
$$

The other variant, marked GP, is inspired by the similarity of the form of Equation (4) to Equation (3) of the Gough and Pollard criterion:

$$
a_{K P, G P}=\kappa-1
$$

The last version $a_{N K}$ is similarly inspired by the criterion proposed by Nishihara and Kawamoto [38], which leads to

$$
a_{K P, N K}=\left(\kappa^{2}-1\right) / 2 .
$$

It should be noted, however, that only the derivation of $a_{K P, O P}$ is rigorous, and thus the other parameters $a_{K P, N K}$ and $a_{K P, G P}$ are expected to lead to erroneous results for the pure torsion load case, and logically also elsewhere.

The KP criterion is not dependent on the phase shift between normal stress and shear stress. Khalij et al. [36] see it legitimate as many other authors (see, e.g., [39]), though Sonsino [40] or Papuga [41,42] devoted some effort to explaining that such an independence is far from proven. The extension of the original Gough and Pollard criterion to the general plane stress state is still insufficient for common applicability. The plane stress state is achieved on a free unloaded surface only, and thus, e.g., computation of any pressurized vessel or of some contact interface can reach the limits of an applicability of the KP criterion.

\subsubsection{Wang and Shang Criterion}

The Wang and Shang (WS) damage parameter is defined in [43]. It is composed of normal stresses acting on the critical plane (amplitude value $N_{a}$ and mean value $N_{m}$ ) and of relevant shear stresses on the same plane (amplitude value $C_{a}$ and mean value $C_{m}$ ):

$$
\sigma_{e q, W S}=\sqrt{\left(a_{W} C_{a}+c_{W} C_{m}\right)^{2}+\left(b_{W} N_{a}+d_{W} N_{m}\right)^{2}} .
$$

The four material parameters $a_{W}-d_{W}$ are derived from the axial and torsion load cases in the fully reversed mode and in the repeated mode of loading: 


$$
\begin{gathered}
a_{W}=\kappa, \\
b_{W}=\frac{\kappa}{\sqrt{3}} \\
c_{W}=\frac{2 s_{-1}}{t_{0}}-\kappa, \\
d_{W}=\sqrt{\frac{16 s_{-1}^{2}}{s_{0}^{2}}-\frac{4 s_{-1}^{2}}{t_{0}^{2}}}-\frac{\kappa}{\sqrt{3}}
\end{gathered}
$$

In the formulation of Equation (9), the WS criterion resembles other critical plane criteria, see, e.g., the PCN criterion hereafter. The specific point in using this criterion according to Wang et al. is the way in which the critical plane is determined. Here comes the important limitation, because to keep the calculation simple, the authors of [43] focus solely on the combination of axial and torsion loads. Thanks to the simple load case, the maximum shear stress $T_{\max }$ acting in current time $t$ of the stress cycle can be simply computed from axial and shear stresses.

Such evaluation treats only planes perpendicular to the surface (i.e., only these planes are examined in this criterion, though, e.g., Bannantine and Socie [44] proposed to examine also the planes inclined by $45^{\circ}$ to the surface), because the authors refer to Papadopoulos et al. [39], who also focused only on those planes stating that this is the only fracture mode observed for bending-torsion load combination. The angle between the evaluated plane and the maximum shear stress plane $\varphi(t)$ can be simply derived from the Mohr's circle. The angle to locate the critical plane is then obtained from a weighted average over all the angles $\varphi(t)$ calculated within the load cycle period:

$$
\begin{gathered}
\varphi_{W}=\operatorname{sign}\left[\sum_{t} \varphi(t) \cdot W(t)\right] \cdot \frac{1}{W_{t o t}} \sum_{t}|\varphi(t)| \cdot W(t) \\
\text { where } W_{\text {tot }}=\sum_{t} W(t) .
\end{gathered}
$$

This way of definition of the critical plane results in two stress states rotated by $90^{\circ}$ one from another. From these two planes, the one reaching the higher equivalent stress $\sigma_{\text {eq,WS }}$ Equation (9) is chosen as the critical plane. The weight $W(t)$ used to define the final critical plane orientation $\varphi_{W}$ is established from current values of the maximum shear stress $T_{\max }(t)$ and from its maximum and minimum values throughout the load cycle:

$$
W(t)=\frac{T_{\max }(t)-\min _{t}\left(T_{\max }(t)\right)}{\max _{t}\left(T_{\max }(t)\right)-\min _{t}\left(T_{\max }(t)\right)}
$$

If the KP criterion is defined only for plane stress state, in which two normal stresses and one shear stress are applied concurrently, the WS criterion presents even more substantial limitation, because it is postulated solely for the case of concurring axial and torsion loads. Technically, the criterion could be extended to cover full stress tensor input, but this would call for an involvement of the other angle that defines the critical plane orientation-similar, e.g., to the concept of weighted critical plane orientation proposed by Carpinteri et al. [45]. Such an extension would raise many questions that would have to be answered first. Because of that, this paper focuses solely on this current definition, which means that the part of the data set will not be evaluated.

\subsubsection{Böhme Criterion}

The recently published criterion [46] was derived by its author to deal well with fatigue in gear teeth, where not only the fatigue response on the surface of the gear tooth was analyzed, but the same criterion should also be applicable in the gear tooth core. This requirement is induced by the fact that the case-hardened gears have substantially different properties on the surface and in the core and that the observed failures can be initiated deep below the surface in the area where the case ends. The aforementioned KP or WS 
criteria would fail to provide an answer for this configuration because the stress state is more complicated than their inputs allow. In the development, Böhme focused on integral criteria only, and the final configuration, which he found optimum, is:

$$
\sigma_{e q, B}=\sqrt{\frac{15}{8 \pi} \int_{\varphi=0}^{2 \pi} \int_{\theta=0}^{\pi}\left[\left(a_{B} C_{a}^{2}+b_{B} N_{a}^{2}\right)\left(1+d_{B} N_{m}\right)^{2}+c_{B} C_{a} C_{m}\right] \sin \theta d \theta d \varphi}
$$

The material parameters necessary for the computation are as follows:

$$
\begin{gathered}
a_{B}=\frac{1}{5}\left(3 \kappa^{2}-4\right), \\
b_{B}=\frac{2}{5}\left(3-\kappa^{2}\right) \\
c_{B}=\frac{\kappa^{2}}{3}\left[\left(\frac{2 t_{-1}}{t_{0}}\right)^{2}-\frac{d_{B}^{2} t_{0}^{2}}{35 \kappa^{2}}\left(8-\kappa^{2}\right)-1\right] \\
d_{B}=\sqrt{\left[\frac{3 s_{0}\left(11-2 \kappa^{2}\right)}{70 C}\right]^{2}+\frac{1}{C}\left[\left(\frac{2 s_{-1}}{s_{0}}\right)^{2}-\frac{1}{3}\left(\frac{2 s_{-1}}{t_{0}}\right)^{2}+\frac{\kappa^{2}}{3}-1\right]}-\frac{3 s_{0}\left(11-2 \kappa^{2}\right)}{70 C}
\end{gathered}
$$

Here an additional material parameter $C$ had to be introduced to shorten the record:

$$
C=\frac{s_{0}^{2}}{84}\left(17-4 \kappa^{2}\right)-\frac{t_{0}^{2}}{105}\left(8-\kappa^{2}\right)
$$

The criterion is identical to the Liu-Zenner criterion [47]:

$$
\sigma_{e q, L Z}=\sqrt{\frac{15}{8 \pi} \int_{\varphi=0}^{2 \pi} \int_{\theta=0}^{\pi}\left[a_{L Z} C_{a}^{2}\left(1+c_{L Z} C_{m}^{2}\right)+b_{L Z} N_{a}^{2}\left(1+d_{L Z} N_{m}\right)\right] \sin \theta d \theta d \varphi,}
$$

if there is no mean stress involved. The basic difference is the way the mean stress effect is implemented. Böhme had to deal with compressive mean stresses in his tasks, and he wanted to ensure that negative mean normal stress will not lead to decreasing equivalent stress down to negative values below the square root, while the mean shear stress effect should be involved in some way.

The authors of [46] benchmarked several criteria on the test set that comprises 23 load cases derived from the FatLim database, which included both axial mean stress and the shear stress amplitude. The Böhme criterion was only slightly worse than the best performing PIN criterion [17], which, however, failed to provide adequate damage distribution for analysis of real gear teeth.

\subsubsection{Criterion}

The MDC criterion (Margetin-Ďurka-Chmelko) was published in [48] in a comparison with several other criteria in a fatigue life analysis. The formulation for fatigue life estimation presented there can be simply reconfigured to result in the fatigue strength evaluation:

$$
\sigma_{e q, M}=a_{M} \sqrt{C_{a}^{2}+N_{\max }^{2}\left(b_{M} N_{\max }^{g}-1\right)} .
$$

The material parameters necessary for the solution are provided by the authors:

$$
\begin{gathered}
a_{M}=\kappa, \\
b_{M}=\left(\frac{2 \tau_{f}^{\prime}}{\sigma_{f}^{\prime}}\right)^{2}\left(\frac{2}{\sigma_{f}^{\prime}}\right)^{g}, \\
g=\frac{2\left(b_{t}-b\right)}{b}
\end{gathered}
$$


The critical plane in the authors' definition is the plane with the maximum shear stress range detected. The fact that the criterion was designed for the calculation of the fatigue life $N_{f}$ can be seen in the definition of the material parameters, which include the parameters $\sigma_{f}^{\prime}$ and $b$ of the Basquin formula for the fully reversed axial load:

$$
\sigma_{a}=\sigma_{f}^{\prime}\left(2 N_{f}\right)^{b}
$$

and similar parameters $\tau_{f}^{\prime}$ and $b_{t}$ should be recovered for the fully reversed torsion case. The method was successfully tested in [48] on own experimental data of a common structural steel S355, while the output was much worse for the very ductile C55 steel (this lack of prediction quality in that case was similar, however, to the output of most methods tested in [48]).

Within the benchmark tasks analyzed in the current paper, the important limitation imposed by the formulation of the criterion is the necessity to deal with the description of the Basquin curves. This restrains the application of the method to all cases in the FatLim data set, which are derived from fatigue experiments via the staircase method, because the description of the Basquin curve is not available for them.

\subsubsection{Mertens' Criterion MMMH, and the Derived Formula M3HW}

The MMMH (Modified Mises-Mohr Hypothesis) is the invariant based criterion published by Mertens et al. [49-51]. With the aim of considering also non-proportional stresses in fatigue analysis, it features a sign determination. First, the equivalent stress is calculated without the involvement of mean stresses. In the configuration intended for evaluating the surface of smooth unnotched samples included in FatLim (up to three normal stresses, one shear stress), the formula follows:

$$
\sigma_{e q, M M M H}(t)=V_{M}(t) \cdot \sqrt{\left(4-\kappa^{2}\right) \cdot M_{M}^{2}(t)+\kappa^{2} \cdot R_{M}^{2}(t)},
$$

$M_{M}$ and $R_{M}$ represent the invariant modules of the hypothesis:

$$
\begin{gathered}
M_{M}(t)=\frac{\sigma_{x}(t)+\sigma_{y}(t)}{2}-\sigma_{z}(t), \\
R_{M}(t)=V_{R} \cdot \sqrt{\left(\frac{\sigma_{x}(t)-\sigma_{y}(t)}{2}\right)^{2}-\tau_{x y}^{2}(t)}
\end{gathered}
$$

It must be mentioned explicitly to ensure the validity of Equation (21) that the coordinate system must be oriented in such a way that $x$ and $y$ axes are tangential to the evaluated surface, while $z$-axis is perpendicular to the surface (e.g., acting pressure). The parameter $V_{M}(t)$ is a sign function derived from:

$$
V_{M}(t)=\operatorname{sign}\left[\sqrt{4-\kappa^{2}} \cdot M_{M}(t)+\kappa \cdot R_{M}(t)\right] .
$$

On the other hand, $V_{R}$ designates another sign function, the output of which is, however, much more complicated based on various possible configurations. For its computation, reading [49] is recommended.

The final equivalent stress amplitude is calculated as half of the difference between the maximum and minimum values of the current equivalent stress within the load cycle:

$$
\sigma_{e q, a, M M M H}=\left[\max _{t} \sigma_{e q, M M M H}(t)-\min _{t} \sigma_{e q, M M M H}(t)\right] / 2,
$$


In the case of an unnotched specimen loaded within the high-cycle fatigue regime, the calculation of the equivalent mean stress stated in [51] is simplified to:

$$
\sigma_{e q, m, M M M H}=\left[\max _{t} \sigma_{1}(t)-\min _{t} \sigma_{3}(t)\right] / 2 \text {. }
$$

where $\sigma_{1}$ is the maximum principal stress and $\sigma_{3}$ is the minimum principal stress. Using the following expressions, the mean stress effect is considered according to [51] to calculate the amplitude of the reduced fatigue strength $s_{-1, \text { red }}$ :

$$
\begin{gathered}
M=\frac{s_{-1}-s_{0} / 2}{s_{0} / 2} \\
Q=\frac{M \cdot(2+M)}{1+2 \cdot M} \\
s_{-1, \text { red }}=s_{-1} \cdot \frac{-Q+\sqrt{Q^{2}+4(1-Q)\left(1-Q \sigma_{e q, m, M M M H} / s_{-1}\right)}}{2(1-Q)}
\end{gathered}
$$

The computed equivalent stress amplitude $\sigma_{e q, a, M M M H}$ should thus be compared with this value to check if the stress state record exceeds or stays below the limit state. Unfortunately, the MMMH criterion in this version ended up with such a bad prediction quality for cases with high mean stresses that its simple rearrangement according to the Walker formula is proposed here to the new version of the criterion marked as M3HW:

$$
\sigma_{e q, M 3 H W}=\left(\sigma_{e q, a, M M M H}+\sigma_{e q, m, M M M H}\right)^{(1-w)} \cdot \sigma_{e q, a, M M M H}^{w} .
$$

The Walker formula was chosen because Papuga et al. highlighted its good predictive properties on a broad data set in [52]. The formula contains the Walker coefficient $w$, which allows its user to better tune the mean stress effect based on the available experimental data:

$$
w=\frac{\log \left(\frac{s_{0}}{s_{-1}}\right)}{\log 2}
$$

\subsubsection{Yankin Criterion}

The authors of [53] modified the original Sines criterion [19] by introducing two more terms into the formula so that the combined influence of cyclic normal and shear stresses could be effectively weighted from the point of view of both the amplitude and mean values. The new version, denoted as Sines++ in [53], was proposed to estimate fatigue life. It can be simply converted to the equivalent stress formula, which is expressed as:

$$
\sigma_{e q, Y}=\sqrt{\left(a_{Y} \sqrt{J_{2 a}}\right)^{2}+\left(c_{Y} \sqrt{J_{2 m}}\right)^{2}}+b_{Y} I_{1 a}+d_{Y} I_{1 m}
$$

where $\sqrt{J_{2 a}}$ and $\sqrt{J_{2 m}}$ are amplitude and mean values of the second invariant of the stress tensor deviator. Their calculation was implemented by Yankin et al. in the following form:

$$
\sqrt{J_{2 a}}=\frac{1}{\sqrt{6}} \sqrt{\left(\sigma_{x a}-\sigma_{y a}\right)^{2}+\left(\sigma_{y a}-\sigma_{z a}\right)^{2}+\left(\sigma_{x a}-\sigma_{z a}\right)^{2}+6\left(\tau_{x y a}^{2}+\tau_{y z a}^{2}+\tau_{x z a}^{2}\right)}
$$

and

$$
\sqrt{J_{2 m}}=\frac{1}{\sqrt{6}} \sqrt{\left(\sigma_{x m}-\sigma_{y m}\right)^{2}+\left(\sigma_{y m}-\sigma_{z m}\right)^{2}+\left(\sigma_{x m}-\sigma_{z m}\right)^{2}+6\left(\tau_{x y m}^{2}+\tau_{y z m}^{2}+\tau_{x z m}^{2}\right)} .
$$


Amplitude and mean values of the first invariant of the stress tensor, $I_{1 a}$ and $I_{1 m}$, are calculated as follows:

$$
\begin{gathered}
I_{1 a}=\sigma_{x a}+\sigma_{y a}+\sigma_{z a}, \\
I_{1 m}=\sigma_{x m}+\sigma_{y m}+\sigma_{z m} .
\end{gathered}
$$

The model parameters were derived by the authors to be:

$$
a_{Y}=\kappa, \quad b_{Y}=1-\frac{\kappa}{\sqrt{3}}, \quad c_{Y}=\frac{s_{-1}}{R_{m t}}, \quad d_{Y}=\frac{s_{-1}}{R_{m}}-\frac{s_{-1}}{\sqrt{3} R_{m t}},
$$

where $R_{m}$ and $R_{m t}$ are ultimate tensile strengths in tension and torsion, respectively.

Note that the proposed means of evaluating the $\sqrt{J_{2 a}}$ and $\sqrt{J_{2 m}}$ in Equations (29) and (30) is suitable rather for in-phase loading. Since the FatLim database also contains a number of multiaxial experiments applied with a phase shift of the load channels, the analytical approach to calculate the minimum circumscribed sphere in the stress deviatoric space [42] was adopted in this study instead of Equations (29) and (30).

The calculation of the criterion in cases involving mean stresses is dependent on the value of the ultimate shear strength, which is a value only rarely available in published experimental data sets, see its sparse appearance among the material properties for data sets used in AMSD25 in Table 2. This limitation means that the method could be applied only to 80 data items from the complete FatLim benchmark set. To increase a bit the credibility of validating the Yankin criterion in the AMSD25 data set, an attempt was made to estimate the $R_{m t}$ value from $R_{m}$. Commonly in machine design, either von Mises stress theory or Tresca stress theory are used to derive $R_{m t}=0.58 R_{m}$ or $R_{m t}=0.5 R_{m}$, respectively. However, those few cases, where both these material parameters are present, lead to $R_{m t}$ from $0.76 R_{m}$ to $0.92 R_{m}$, i.e., to values substantially higher than those two, apparently conservative, theories. Because of that, the proposals of this relation from the handbook [54] are used in the following form:

$$
\begin{gathered}
\text { Steels : } R_{m t}=0.75 R_{m}, \\
\text { Cast iron : } R_{m t}=1.30 R_{m}, \\
\text { Copper alloys : } R_{m t}=0.65 R_{m}, \\
\text { Aluminum alloys : } R_{m t}=0.65 R_{m},
\end{gathered}
$$

Yankin's model analysis using this set of formulas to derive the missing $R_{m t}$ values is marked DMW hereafter, while the one using von Mises stress is marked VM. The results of both versions coincide in cases where the experimentally set $R_{m t}$ value is available for its direct application.

\subsubsection{The Reference Criteria}

The equivalent stresses of the individual criteria used as references are gathered in Table 3 together with their material parameters. The PCN criterion is of the critical plane type, with the critical plane set by maximizing the equivalent stress over all possible plane orientations. The PIN criterion is of the integral type involved here to provide a counterpart to the Böhme criterion of the same type. The MMP criterion is a simple solution derived from von Mises equivalent stress, and it could be used as a counterpart to the M3HW (or $\mathrm{MMMH}$ ) criterion. It is intended for quick calculations, e.g., within MS Excel, while it still ensures quite good prediction quality.

The Dang Van criterion in the implementation used in this study belongs to the critical plane criteria. In this method, the detected maximum shear stress range defines the critical plane. In this paper, the common formulation of a linear weighted combination of the instantaneous shear stress excursion and of the current hydrostatic stress is used. This variant is frequently used in various fatigue solvers. Papuga et al. have previously shown [10] that the modified formulation combining the maximum shear stress amplitude with maximum hydrostatic stress provides better results, because of the improved behavior 
under out-of-phase loading. The too extreme response to dephasing between axial and shear stresses detected by the original formulation of the Dang Van criterion was also confirmed in [41]. However, the reference to the current status quo is desired in this paper, and so this original and frequently used formulation is used here.

Table 2. Description of the materials used within the AMSD25 data sets and of their material parameters necessary to calculate the equivalent stresses by the criteria assessed in this paper. All fatigue strengths presented here refer to the same number of cycles as the load cases described in Tables 4-9.

\begin{tabular}{|c|c|c|c|c|c|c|c|c|c|c|c|c|}
\hline Set & Material & $\begin{array}{c}\boldsymbol{R}_{m} \\
\text { (MPa) }\end{array}$ & $\begin{array}{c}\boldsymbol{R}_{m t} \\
(\mathrm{MPa})\end{array}$ & $\begin{array}{c}R_{e} \\
(\mathrm{MPa})\end{array}$ & $\begin{array}{c}s_{-1} \\
(\mathrm{MPa})\end{array}$ & $\begin{array}{c}s_{0} \\
(\mathrm{MPa})\end{array}$ & $\begin{array}{c}t_{-1} \\
(\mathrm{MPa})\end{array}$ & $\begin{array}{c}t_{0} \\
(\mathrm{MPa})\end{array}$ & $b(-)$ & $\begin{array}{c}\sigma_{f}^{\prime} \\
(\mathbf{M P a})\end{array}$ & $b_{t}(-)$ & $\begin{array}{c}\tau_{f}^{\prime} \\
(\mathrm{MPa})\end{array}$ \\
\hline AR1 & 42CrMo4 & 1100 & & 980 & 488.2 & & 403.8 & & -0.102 & 1820 & -0.066 & 948 \\
\hline $\mathrm{BaB}$ & Ck35 & 706 & 569 & 539 & 342.1 & 540.5 & 230.0 & 430.3 & -0.068 & 784 & -0.089 & 649 \\
\hline Bai & 34CrMo4 & 902 & 814 & 706 & 430.7 & 683.7 & 318.6 & 574.2 & -0.073 & 1087 & -0.088 & 994 \\
\hline BKL & 100Cr6 & 2467 & & 2115 & 866.0 & 1060.0 & 541.0 & & & & & \\
\hline FAD & 2124-T851 & 477 & 365 & 439 & 153.4 & 238.6 & 109.1 & 178.0 & -0.190 & 2099 & -0.113 & 514 \\
\hline FAD * & 2124-T851 & 477 & 365 & 440 & 198.3 & 258.7 & 110.0 & 0.0 & -0.127 & 1146 & -0.129 & 655 \\
\hline $\mathrm{FF}$ & ČSN 411523 & 560 & 517 & 400 & 244.5 & 385.3 & 169.0 & 330.5 & -0.061 & 582 & -0.028 & 252 \\
\hline Fin & 76S-T61 & 508 & 419 & 470 & 262.3 & 377.8 & 172.6 & 288.6 & -0.105 & 1043 & -0.100 & 634 \\
\hline GrN & GGG-60 & 635 & & 425 & 318.0 & 400.0 & 225.0 & 411.0 & -0.097 & 1109 & -0.095 & 764 \\
\hline Han & SAE4340 & 844 & & 732 & 541.8 & 1028.5 & 365.2 & & -0.145 & 3611 & -0.093 & 1211 \\
\hline $\mathrm{HeG}$ & GGG-60 & 815 & & 516 & 275.0 & 392.0 & 249.0 & & & & & \\
\hline KLN & 2017A-T4 & 545 & & 395 & 177.5 & 244.2 & 104.5 & 150.8 & -0.132 & 1215 & -0.146 & 885 \\
\hline KLU & 6082-T6 & 290 & & 230 & 164.9 & & 84.7 & & -0.124 & 1003 & -0.163 & 902 \\
\hline Mie & 25CrMo4 & 780 & & 660 & 340.0 & 600.0 & 228.0 & & & & & \\
\hline $\mathrm{Mie}^{* *}$ & 25CrMo4 & 780 & & 660 & 361.0 & 600.0 & 228.0 & & & & & \\
\hline PSSB & X2CrNiMo17-12-2 & 416 & & 210 & 313.0 & 0.0 & 258.6 & & -0.048 & 584 & -0.050 & 496 \\
\hline Ra1 & EN-GJV-450 & 498 & & 368 & 185.7 & 236.6 & 185.6 & 268.3 & -0.136 & 1158 & -0.105 & 801 \\
\hline $\mathrm{SaL}$ & $14 \mathrm{~S}-\mathrm{T}$ & 498 & & & 227.1 & 374.8 & 119.7 & 218.9 & -0.098 & 995 & -0.183 & 1954 \\
\hline $\mathrm{SiB}$ & Ck45 & 850 & & 807 & 419.6 & 718.3 & 286.2 & & & & & \\
\hline TAK & 25CrMo4 & 801 & & 672 & 340.0 & 600.0 & 228.0 & & & & & \\
\hline
\end{tabular}

Note: * material properties concern FAD044 load case only, ${ }^{* *}$ material properties concern Mie03 load case only.

\subsection{Method of Assessment}

The equivalent stresses computed by various criteria described in Section 2.2 are compared with the experimentally set fatigue strengths in fully reversed axial loading $s_{-1}$ (presented in Table 2 in Section 2.1 for the materials involved in the AMSD25 data set). All fatigue strengths of the materials presented in Table 2 relate to the same numbers of cycles as the multiaxial load cases presented and analyzed in Tables 4-9. If the individual formulas of criteria had been correct, the equivalent stress and the fatigue strength for each data item in the benchmark set would be the same. As this is practically impossible, the fatigue index error $\triangle F I$ is defined as a relative error:

$$
\Delta F I=\frac{\sigma_{e q}-s_{-1}}{s_{-1}}
$$

The values of $\Delta F I$ equal to zero correspond to a rare perfect estimate, the positive values concern cases of too safe (conservative) estimates, and the negative values relate to unsafe (non-conservative) estimates.

There is one exception among the criteria, in which the equivalent stress is not directly computed - the KP criterion. The left-hand side (LHS) of Equation (4) is compared there with unity. That means that for this special case, $\Delta F I$ is defined in a different way:

$$
\Delta F I_{K P}=L H S_{K P}-1
$$


Table 3. Formulations of individual reference multiaxial fatigue strength criteria.

\begin{tabular}{|c|c|c|c|}
\hline Abbrev. & Ref. & Formula of $\sigma_{e q}$ & \\
\hline $\mathrm{PCN}$ & [10] & $\begin{array}{c}\sigma_{e q, P C}=\sqrt{a_{P C} C_{a}\left(C_{a}+c_{P C} C_{m}\right)+b_{P C} \sqrt{N_{a}\left(N_{a}+d_{P C} N_{m}\right)}} \\
1 \leq \kappa<\sqrt{\frac{4}{3}}: a_{P C}=\frac{\kappa^{2}}{2}+\frac{\sqrt{\kappa^{4}-\kappa^{2}}}{2}, b_{P C}=s_{-1} \\
1 \leq \kappa_{0}<\sqrt{\frac{4}{3}}: c_{P C}=\frac{2 s_{-1}^{2}}{a_{P C} \cdot t_{0}^{2}} \cdot\left(1+\sqrt{1-\frac{1}{\kappa_{0}^{2}}}\right)-1, d_{P C}=\left(\frac{2 s_{-1}^{2}}{b_{P C} \cdot s_{0}}\right)^{2}-1 \\
\kappa \geq \sqrt{\frac{4}{3}}: a_{P C}=\left(\frac{4 \cdot \kappa^{2}}{4+\kappa^{2}}\right)^{2}, b_{P C}=8 \cdot s_{-1} \cdot \kappa^{2} \cdot \frac{4-\kappa^{2}}{\left(4+\kappa^{2}\right)^{2}} \\
\kappa_{0} \geq \sqrt{\frac{4}{3}}: c_{P C}=\frac{z}{a_{P C}}-1, d_{P C}=\frac{z}{b_{P C}{ }^{2}} \cdot\left(4 \cdot s_{-1}^{2}-z \cdot t_{0}^{2}\right)-1, z=\left[\frac{8 \cdot \kappa_{0} \cdot s_{-1}}{t_{0} \cdot\left(4+\kappa_{0}^{2}\right)}\right]^{2}\end{array}$ & $(34)$ \\
\hline PIN & {$[17]$} & $\begin{array}{c}\sigma_{e q, P I}=\sqrt{\frac{1}{4 \pi} \int_{\varphi=0}^{2 \pi} \int_{\theta=0}^{\pi}\left[a_{P I} C_{a}\left(C_{a}+c_{P I} C_{m}\right)+b_{P I}\left(N_{a}+d_{P I} N_{m}\right)\right] \sin \theta d \theta d \varphi} \\
a_{P I}=\frac{15}{2} \cdot \kappa \cdot\left(\frac{\pi \cdot \kappa-4}{3 \pi-4 \kappa}\right), \quad b_{P I}=3 \cdot s_{-1} \cdot\left[1-\kappa \cdot\left(\frac{\pi \cdot \kappa-4}{3 \pi-4 \kappa}\right)\right] \\
c_{P I}=10 \frac{s_{-1}^{2}}{a_{P I} t_{0}^{2}}-\frac{20}{3} \frac{b_{P I}}{\pi a_{P I} t_{0}}-1, \quad d_{P I}=6 \frac{s_{-1}^{2}}{b_{P I} s_{0}}\left(1-\frac{s_{0}^{2}}{3 t_{0}^{2}}\right)+\frac{4}{3} \frac{s_{0}}{\pi t_{0}}-1\end{array}$ & $(35)$ \\
\hline MMP & {$[30]$} & 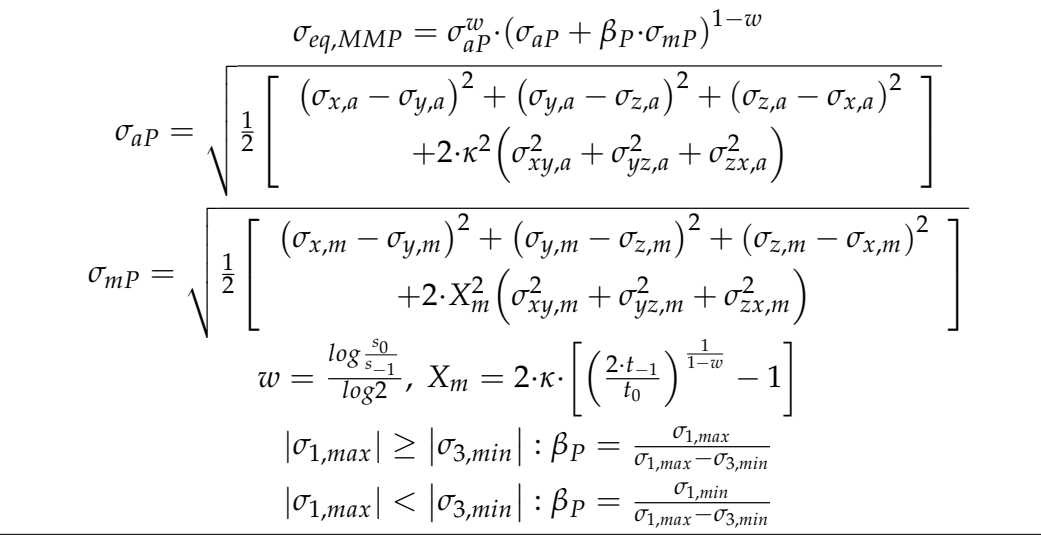 & $(36)$ \\
\hline DV & [33] & $\begin{array}{c}\sigma_{e q, D V}=\max _{t}\left[a_{D V} \cdot C_{a}(t)+b_{D V} \cdot \sigma_{H}(t)\right] \\
a_{D V}=\kappa, \quad b_{D V}=3-\frac{3}{2} \cdot \kappa\end{array}$ & $(37)$ \\
\hline
\end{tabular}

Fatigue experiments tend to result in some scatter. Secondly, though the scope of analyses performed to build up the FatLim set was tremendous and many potential items were filtered out [32], it still relies on second-hand data. Some specific details that would cause some given data items to be rejected can stay hidden. It is thus reasonable not to rely on individual data items only but to validate the criteria on data sets as broad as possible, so that the effect of such mishaps was marginalized.

The results gathered in the next section will thus refer to individual load cases only for the AMSD25 data set [31], i.e., to data items, which generate either a large deviation from zero $\Delta F I$ or a large scatter in the prediction quality for most fatigue strength criteria. This complete printout can also serve as some kind of a reference for future research papers dealing with new criteria. To get the information of the prediction quality overall and in particular subsets, however, the $\Delta F I$ statistics over specific FatLim (sub)sets will be used and presented. The most important parameters of the statistical analysis are listed below:

- The average value (Aver.) shows the potential bias of the method to produce too conservative or too non-conservative results. The closer to zero, the better.

- The standard deviation value (SD) shows the overall scatter of the data. The smaller, the better.

- The maximum value (Max.) shows the potential tendency of the method to produce outliers in the conservative direction. The closer to zero, the better.

- The minimum value (Min.) shows the potential tendency of the method to produce outliers in the non-conservative direction. The closer to zero, the better. 
Apart from evaluating the overall statistical report, subgroups of various load cases are formed and analyzed within this paper to provide an information about characteristic behavior of individual criteria in given situations. The most important such groups are:

- $\quad\{\mathrm{Ax}\}-39$ items: only axial load cases;

- $\quad\{$ To\}-20 items: only torsion load cases;

- $\quad\{\mathrm{MS}\}$-196 items: load cases, when at least one mean stress is active;

- $\quad\{$ MS- $\}$-40 items: load cases, where some normal mean stress is compressive;

- $\quad\{$ nMS -88 items: load cases with no mean stress involved;

- $\{\mathrm{NP}\}-123$ items: non-proportional load cases that cause the principal directions to rotate (also, e.g., one constant load channel and the other one non-constant);

- $\quad\{\mathrm{IP}\}-102$ items: in-phase load cases (the principal directions remain fixed);

- $\quad\{\mathrm{IP}, \mathrm{nMS}\}-59$ items: intersection of $\{\mathrm{IP}\}$ and $\{\mathrm{nMS}\}$ groups;

- $\quad\{\mathrm{OOP}\}-74$ items: subgroup of $\{\mathrm{NP}\}$ set; out-of-phase cases, in which the rotation of principal directions is caused by the non-zero phase shift between stress components;

- $\quad\{\mathrm{OOP}, \mathrm{nMS}\}-29$ items: intersection of $\{\mathrm{OOP}\}$ and $\{\mathrm{nMS}\}$ groups.

\section{Results}

The results of computations are reported in Tables 4-9 for the AMSD25 data set. They are grouped into three different load case types. Tables 4 and 5 concern the combination of tension and torsion, where the loading description is covered in Table 4 together with the fatigue response of the reference criteria, while Table 5 describes the response of newly evaluated methods. A similar composition is used in Tables 6 and 7, which focus on plane bending and torsion combination, and in Tables 8 and 9, which cover the load cases including the second and third normal stress channels induced usually by pressurizing a hollow sample.

Table 4. Tension-torsion load cases in the AMSD25 data set and the response of reference multiaxial fatigue strength criteria to them.

\begin{tabular}{|c|c|c|c|c|c|c|c|c|c|}
\hline \multirow{2}{*}{ Item } & \multirow{2}{*}{$\sigma_{x a}(\mathrm{MPa})$} & \multirow{2}{*}{$\begin{array}{c}\sigma_{x m} \\
(\mathrm{MPa})\end{array}$} & \multirow{2}{*}{$\begin{array}{c}\tau_{x y a} \\
(\mathrm{MPa})\end{array}$} & \multirow{2}{*}{$\begin{array}{c}\tau_{x y m} \\
(\mathrm{MPa})\end{array}$} & \multirow{2}{*}{$\delta_{x y}\left(^{\circ}\right)$} & \multicolumn{4}{|c|}{$\Delta F I(\%)$} \\
\hline & & & & & & PCN & PIN & MMP & DV \\
\hline AR1004 & 481.6 & 0.0 & 278.1 & 0.0 & 90 & $16.3 \%$ & $14.6 \%$ & $20.3 \%$ & $-1.3 \%$ \\
\hline BaB004 & 331.6 & 0.0 & 0.0 & 304.0 & 0 & $13.8 \%$ & $2.8 \%$ & $-3.1 \%$ & $-3.1 \%$ \\
\hline BaB009 & 0.0 & -549.2 & 281.9 & 0.0 & 0 & $20.5 \%$ & $2.3 \%$ & $-17.8 \%$ & $-18.6 \%$ \\
\hline BaB013 & 0.0 & 588.4 & 155.3 & 0.0 & 0 & $-4.2 \%$ & $6.7 \%$ & $3.6 \%$ & $11.6 \%$ \\
\hline Bai007 & 363.4 & 0.0 & 0.0 & 431.5 & 0 & $4.9 \%$ & $-3.1 \%$ & $-15.6 \%$ & $-15.6 \%$ \\
\hline Bai008 & 353.2 & 0.0 & 0.0 & 647.2 & 0 & $9.1 \%$ & $-2.1 \%$ & $-18.0 \%$ & $-18.0 \%$ \\
\hline Bai011 & 306.1 & 306.1 & 0.0 & 490.3 & 0 & $4.2 \%$ & $-2.4 \%$ & $-13.1 \%$ & $-5.9 \%$ \\
\hline Bai013 & 0.0 & -549.2 & 398.2 & 0.0 & 0 & $22.5 \%$ & $8.0 \%$ & $1.5 \%$ & $-16.4 \%$ \\
\hline Bai016 & 0.0 & 353.0 & 297.9 & 0.0 & 0 & $6.0 \%$ & $8.2 \%$ & $5.0 \%$ & $20.0 \%$ \\
\hline Bai017 & 0.0 & 509.9 & 257.6 & 0.0 & 0 & $0.4 \%$ & $6.1 \%$ & $2.4 \%$ & $19.2 \%$ \\
\hline Bai018 & 0.0 & 696.3 & 210.9 & 0.0 & 0 & $-5.7 \%$ & $3.5 \%$ & $-1.2 \%$ & $18.6 \%$ \\
\hline BKL01 & 503.0 & 614.8 & 0.0 & 0.0 & 0 & $1.0 \%$ & $2.1 \%$ & $1.3 \%$ & $-27.7 \%$ \\
\hline BKL02 & 437.0 & 1019.7 & 0.0 & 0.0 & 0 & $7.8 \%$ & $14.2 \%$ & $11.7 \%$ & $-26.0 \%$ \\
\hline BKL03 & 417.0 & 1251.0 & 0.0 & 0.0 & 0 & $11.5 \%$ & $21.5 \%$ & $18.0 \%$ & $-23.0 \%$ \\
\hline BKL04 & 372.0 & 1488.0 & 0.0 & 0.0 & 0 & $12.4 \%$ & $26.2 \%$ & $19.0 \%$ & $-22.7 \%$ \\
\hline BKL06 & 607.0 & 0.0 & 303.5 & 0.0 & 90 & $-11.7 \%$ & $-9.7 \%$ & $-10.2 \%$ & $-29.9 \%$ \\
\hline BKL08 & 417.0 & 509.7 & 208.5 & 0.0 & 90 & $-0.9 \%$ & $-2.2 \%$ & $-5.9 \%$ & $-40.1 \%$ \\
\hline FAD003 & 66.3 & 375.6 & 0.0 & 0.0 & 0 & $-3.2 \%$ & $0.1 \%$ & $-6.3 \%$ & $15.9 \%$ \\
\hline FAD011 & 58.9 & 58.9 & 58.9 & 58.9 & 90 & $-8.3 \%$ & $-9.0 \%$ & $-27.6 \%$ & $-33.0 \%$ \\
\hline FAD012 & 0.0 & 0.0 & 65.3 & 196.4 & 0 & $-4.2 \%$ & $-5.1 \%$ & $-40.2 \%$ & $-40.2 \%$ \\
\hline
\end{tabular}


Table 4. Cont.

\begin{tabular}{|c|c|c|c|c|c|c|c|c|c|}
\hline \multirow{2}{*}{ Item } & \multirow{2}{*}{$\sigma_{x a}(\mathbf{M P a})$} & \multirow{2}{*}{$\begin{array}{c}\sigma_{x m} \\
(\mathbf{M P a})\end{array}$} & \multirow{2}{*}{$\begin{array}{c}\tau_{x y a} \\
(\mathrm{MPa})\end{array}$} & \multirow{2}{*}{$\begin{array}{c}\tau_{x y m} \\
(\mathrm{MPa})\end{array}$} & \multirow{2}{*}{$\delta_{x y}\left(^{\circ}\right)$} & \multicolumn{4}{|c|}{$\Delta F I(\%)$} \\
\hline & & & & & & PCN & PIN & MMP & DV \\
\hline FAD014 & 55.7 & 55.7 & 55.8 & 55.7 & 0 & $-11.4 \%$ & $-14.1 \%$ & $-27.4 \%$ & $-21.2 \%$ \\
\hline FAD044 & 86.4 & 259.2 & 0.0 & 0.0 & 0 & $-1.2 \%$ & $10.3 \%$ & $-2.1 \%$ & $-43.6 \%$ \\
\hline GrN003 & 146.1 & 146.1 & 84.7 & 84.7 & 0 & $-3.8 \%$ & $-8.2 \%$ & $-14.0 \%$ & $-23.3 \%$ \\
\hline HeG02 & 221.0 & 0.0 & 110.5 & 0.0 & 90 & $-2.8 \%$ & $1.7 \%$ & $-8.2 \%$ & $-19.6 \%$ \\
\hline HeG06 & 271.0 & -135.5 & 135.5 & 135.5 & 180 & $-2.4 \%$ & $-0.1 \%$ & $-21.1 \%$ & $-1.0 \%$ \\
\hline Mie03 & 338.0 & -338.0 & 0.0 & 0.0 & 0 & $-22.4 \%$ & $-6.2 \%$ & $-30.4 \%$ & $-25.9 \%$ \\
\hline PSSB003 & 302.0 & 0.0 & 151.0 & 0.0 & 90 & $10.8 \%$ & $10.7 \%$ & $12.8 \%$ & $-3.5 \%$ \\
\hline Ra1001 & 59.4 & 415.6 & 0.0 & 0.0 & 0 & $3.6 \%$ & $19.5 \%$ & $7.3 \%$ & $43.8 \%$ \\
\hline Ra1002 & 82.1 & 246.3 & 0.0 & 0.0 & 0 & $1.3 \%$ & $6.7 \%$ & $2.6 \%$ & $10.5 \%$ \\
\hline Ra1004 & 282.0 & -169.2 & 0.0 & 0.0 & 0 & $-15.4 \%$ & $7.9 \%$ & $4.5 \%$ & $6.3 \%$ \\
\hline Ra1033 & 0.0 & 0.0 & 134.2 & 134.2 & 0 & $6.5 \%$ & $0.2 \%$ & $-27.7 \%$ & $-27.7 \%$ \\
\hline
\end{tabular}

Table 5. The response of evaluated new multiaxial fatigue strength criteria to the tension-torsion load cases from AMSD25 data set. The void cells in the MDC column mark the load cases run in the staircase scheme, which does not provide material parameters required by the MDC criterion for its calculation

\begin{tabular}{|c|c|c|c|c|c|c|c|c|c|}
\hline \multirow{3}{*}{ Item } & \multicolumn{9}{|c|}{$\Delta F I(\%)$} \\
\hline & \multicolumn{3}{|c|}{ KP } & \multirow{2}{*}{ WS } & \multirow{2}{*}{ Böhme } & \multirow{2}{*}{ MDC } & \multirow{2}{*}{ M3HW } & \multicolumn{2}{|c|}{ Yankin } \\
\hline & NK & OP & GP & & & & & VM & DMW \\
\hline AR1004 & $45.8 \%$ & $45.4 \%$ & $45.8 \%$ & $-4.4 \%$ & $19.4 \%$ & $21.1 \%$ & $-1.3 \%$ & $-1.3 \%$ & $-1.3 \%$ \\
\hline BaB004 & $9.7 \%$ & $9.3 \%$ & $10.1 \%$ & $26.5 \%$ & $5.3 \%$ & $202.3 \%$ & $20.9 \%$ & $12.6 \%$ & $12.6 \%$ \\
\hline BaB009 & $28.2 \%$ & $28.2 \%$ & $28.2 \%$ & $26.2 \%$ & $-2.7 \%$ & $120.9 \%$ & $22.6 \%$ & $34.6 \%$ & $34.6 \%$ \\
\hline ВаB013 & $4.2 \%$ & $4.2 \%$ & $4.2 \%$ & $73.6 \%$ & $-2.3 \%$ & $312.2 \%$ & $3.8 \%$ & $13.7 \%$ & $13.7 \%$ \\
\hline Bai007 & $3.7 \%$ & $1.2 \%$ & $4.6 \%$ & $-45.2 \%$ & $-5.1 \%$ & $210.8 \%$ & $9.5 \%$ & $3.1 \%$ & $3.1 \%$ \\
\hline Bai008 & $31.7 \%$ & $28.8 \%$ & $32.6 \%$ & $-45.1 \%$ & $-1.3 \%$ & $350.4 \%$ & $16.0 \%$ & $20.1 \%$ & $20.1 \%$ \\
\hline Bai011 & $26.9 \%$ & $22.9 \%$ & $28.2 \%$ & $-17.7 \%$ & $-5.0 \%$ & $330.7 \%$ & $4.5 \%$ & $12.5 \%$ & $12.5 \%$ \\
\hline Bai013 & $42.4 \%$ & $42.4 \%$ & $42.4 \%$ & $37.5 \%$ & $9.9 \%$ & $131.5 \%$ & $25.0 \%$ & $30.9 \%$ & $30.9 \%$ \\
\hline Bai016 & $10.3 \%$ & $10.3 \%$ & $10.3 \%$ & $47.0 \%$ & $11.3 \%$ & $75.1 \%$ & $15.3 \%$ & $10.9 \%$ & $10.9 \%$ \\
\hline Bai017 & $2.0 \%$ & $2.0 \%$ & $2.0 \%$ & $67.2 \%$ & $3.7 \%$ & $153.6 \%$ & $9.2 \%$ & $8.9 \%$ & $8.9 \%$ \\
\hline Bai018 & $-0.3 \%$ & $-0.3 \%$ & $-0.3 \%$ & $84.7 \%$ & $-7.1 \%$ & $266.1 \%$ & $-0.1 \%$ & $10.4 \%$ & $10.4 \%$ \\
\hline BKL01 & $16.0 \%$ & $14.2 \%$ & $20.4 \%$ & $4.9 \%$ & $0.9 \%$ & & $2.3 \%$ & $-36.4 \%$ & $-32.9 \%$ \\
\hline BKL02 & $93.0 \%$ & $91.2 \%$ & $97.5 \%$ & $35.5 \%$ & $11.4 \%$ & & $18.4 \%$ & $-33.9 \%$ & $-30.2 \%$ \\
\hline BKL03 & $151.7 \%$ & $149.9 \%$ & $156.2 \%$ & $55.3 \%$ & $18.8 \%$ & & $28.6 \%$ & $-28.9 \%$ & $-25.5 \%$ \\
\hline BKL04 & $218.6 \%$ & $216.9 \%$ & $223.1 \%$ & $73.5 \%$ & $18.4 \%$ & & $34.3 \%$ & $-24.5 \%$ & $-21.8 \%$ \\
\hline BKL06 & $-14.8 \%$ & $-16.3 \%$ & $-11.0 \%$ & $-17.9 \%$ & $-15.2 \%$ & & $-29.9 \%$ & $-29.9 \%$ & $-29.9 \%$ \\
\hline BKL08 & $-4.8 \%$ & $-6.7 \%$ & $-0.3 \%$ & $17.1 \%$ & $-8.1 \%$ & & $-15.2 \%$ & $-47.3 \%$ & $-44.3 \%$ \\
\hline FAD003 & $191.3 \%$ & $187.1 \%$ & $193.3 \%$ & $66.9 \%$ & $-13.0 \%$ & $-100.0 \%$ & $-14.0 \%$ & $-3.6 \%$ & $-3.6 \%$ \\
\hline FAD011 & $-13.5 \%$ & $-17.5 \%$ & $-11.5 \%$ & $-15.9 \%$ & $-20.4 \%$ & $-11.6 \%$ & $-33.8 \%$ & $-32.6 \%$ & $-32.6 \%$ \\
\hline FAD012 & $98.6 \%$ & $98.6 \%$ & $98.6 \%$ & $0.5 \%$ & $-4.7 \%$ & $-40.2 \%$ & $-9.4 \%$ & $-19.5 \%$ & $-19.5 \%$ \\
\hline FAD014 & $-20.8 \%$ & $-24.7 \%$ & $-18.9 \%$ & $-21.8 \%$ & $-20.1 \%$ & $-13.5 \%$ & $-20.2 \%$ & $-28.7 \%$ & $-28.7 \%$ \\
\hline FAD044 & $87.1 \%$ & $88.1 \%$ & $95.0 \%$ & $13.2 \%$ & $-7.0 \%$ & $-13.4 \%$ & $2.4 \%$ & $-27.3 \%$ & $-27.3 \%$ \\
\hline GrN003 & $2.5 \%$ & $-1.7 \%$ & $4.6 \%$ & $-16.1 \%$ & $-12.0 \%$ & $-18.0 \%$ & $-6.2 \%$ & $-29.2 \%$ & $-23.7 \%$ \\
\hline HeG02 & $-1.7 \%$ & $-6.4 \%$ & $-1.6 \%$ & $-35.0 \%$ & $-7.6 \%$ & & $-19.6 \%$ & $-19.6 \%$ & $-19.6 \%$ \\
\hline HeG06 & $33.3 \%$ & $32.9 \%$ & $33.3 \%$ & $-5.2 \%$ & $-19.6 \%$ & & $26.5 \%$ & $25.2 \%$ & $20.1 \%$ \\
\hline Mie03 & $-16.2 \%$ & $-16.7 \%$ & $-15.2 \%$ & $-18.0 \%$ & $-10.6 \%$ & & $-6.4 \%$ & $4.0 \%$ & $-0.1 \%$ \\
\hline PSSB003 & $29.8 \%$ & $28.9 \%$ & $29.9 \%$ & $-14.5 \%$ & $12.0 \%$ & $70.9 \%$ & $-3.5 \%$ & $-3.5 \%$ & $-3.5 \%$ \\
\hline Ra1001 & $249.8 \%$ & $242.6 \%$ & $249.8 \%$ & $166.5 \%$ & $-3.4 \%$ & $76.7 \%$ & $23.7 \%$ & $-1.0 \%$ & $1.3 \%$ \\
\hline Ra1002 & $95.7 \%$ & $87.5 \%$ & $95.7 \%$ & $68.1 \%$ & $-3.0 \%$ & $39.3 \%$ & $8.9 \%$ & $-25.7 \%$ & $-20.2 \%$ \\
\hline Ra1004 & $9.9 \%$ & $36.2 \%$ & $9.9 \%$ & $10.1 \%$ & $-35.5 \%$ & $0.0 \%$ & $51.8 \%$ & $58.2 \%$ & $53.1 \%$ \\
\hline Ra1033 & $0.0 \%$ & $0.0 \%$ & $0.0 \%$ & $0.0 \%$ & $0.0 \%$ & $-27.7 \%$ & $13.5 \%$ & $-13.9 \%$ & $-24.8 \%$ \\
\hline
\end{tabular}


Table 6. The cases of plane bending-torsion load in the AMSD25 data set and the response of the reference multiaxial fatigue strength criteria to them.

\begin{tabular}{|c|c|c|c|c|c|c|c|c|c|}
\hline \multirow{2}{*}{ Item } & \multirow{2}{*}{$\sigma_{x a}(\mathrm{MPa})$} & \multirow{2}{*}{$\begin{array}{c}\sigma_{x m} \\
(\mathrm{MPa})\end{array}$} & \multirow{2}{*}{$\begin{array}{c}\tau_{x y a} \\
(\mathrm{MPa})\end{array}$} & \multirow{2}{*}{$\begin{array}{c}\tau_{x y m} \\
(\mathrm{MPa})\end{array}$} & \multirow{2}{*}{$\delta_{x y}\left({ }^{\circ}\right)$} & \multicolumn{4}{|c|}{$\Delta F I(\%)$} \\
\hline & & & & & & PCN & PIN & MMP & DV \\
\hline Fin14 & 0.0 & 0.0 & 126.4 & 310.3 & 0 & $4.5 \%$ & $26.6 \%$ & $3.1 \%$ & $-26.8 \%$ \\
\hline Han004 & 504.1 & 713.0 & 0.0 & 0.0 & 0 & $0.0 \%$ & $0.5 \%$ & $0.0 \%$ & $0.1 \%$ \\
\hline Han005 & 492.2 & 862.0 & 0.0 & 0.0 & 0 & $-0.5 \%$ & $0.1 \%$ & $-0.8 \%$ & $-0.6 \%$ \\
\hline KLN06 & 0.0 & 0.0 & 73.4 & 50.0 & 0 & $-10.0 \%$ & $-16.8 \%$ & $-18.1 \%$ & $-29.8 \%$ \\
\hline KLN07 & 0.0 & 0.0 & 78.7 & 75.0 & 0 & $3.1 \%$ & $4.1 \%$ & $-7.5 \%$ & $-24.6 \%$ \\
\hline KLN08 & 0.0 & 0.0 & 68.0 & 100.0 & 0 & $-0.2 \%$ & $5.3 \%$ & $-13.1 \%$ & $-34.9 \%$ \\
\hline KLN09 & 60.8 & 50.0 & 60.8 & 50.0 & 0 & $-4.8 \%$ & $-13.2 \%$ & $-13.6 \%$ & $-19.4 \%$ \\
\hline KLN10 & 53.0 & 75.0 & 53.0 & 75.0 & 0 & $-4.3 \%$ & $-9.1 \%$ & $-14.6 \%$ & $-21.6 \%$ \\
\hline KLN11 & 51.3 & 100.0 & 51.3 & 100.0 & 0 & $1.3 \%$ & $4.7 \%$ & $-9.7 \%$ & $-17.2 \%$ \\
\hline KLN12 & 93.5 & 50.0 & 46.8 & 25.0 & 0 & $-9.4 \%$ & $-19.4 \%$ & $-16.8 \%$ & $-17.9 \%$ \\
\hline KLN13 & 79.4 & 75.0 & 39.7 & 37.5 & 0 & $-12.3 \%$ & $-23.2 \%$ & $-19.5 \%$ & $-21.9 \%$ \\
\hline KLN14 & 65.1 & 136.0 & 32.5 & 68.0 & 0 & $-9.5 \%$ & $-15.9 \%$ & $-17.4 \%$ & $-17.0 \%$ \\
\hline KLU001 & 93.0 & 0.0 & 93.0 & 0.0 & 0 & $19.1 \%$ & $18.5 \%$ & $18.6 \%$ & $15.1 \%$ \\
\hline SaL02 & 182.0 & 198.6 & 0.0 & 0.0 & 0 & $-1.4 \%$ & $-1.5 \%$ & $-1.5 \%$ & $-1.3 \%$ \\
\hline SaL03 & 170.3 & 297.9 & 0.0 & 0.0 & 0 & $-0.1 \%$ & $4.9 \%$ & $1.2 \%$ & $2.8 \%$ \\
\hline SaL04 & 146.3 & 397.1 & 0.0 & 0.0 & 0 & $-4.2 \%$ & $2.6 \%$ & $-2.9 \%$ & $1.5 \%$ \\
\hline SaL07 & 0 & 0 & 86.0 & 231.7 & 0 & $-10.6 \%$ & $-1.6 \%$ & $-9.9 \%$ & $-28.1 \%$ \\
\hline
\end{tabular}

Table 7. The response of the new multiaxial fatigue strength criteria evaluated to the cases of plane bending-torsion load from the AMSD25 data set.

\begin{tabular}{|c|c|c|c|c|c|c|c|c|c|}
\hline \multirow{3}{*}{ Item } & \multicolumn{9}{|c|}{$\Delta F I(\%)$} \\
\hline & \multicolumn{3}{|c|}{ KP } & \multirow{2}{*}{ WS } & \multirow{2}{*}{ Böhme } & \multirow{2}{*}{ MDC } & \multirow{2}{*}{ M3HW } & \multicolumn{2}{|c|}{ Yankin } \\
\hline & NK & OP & GP & & & & & VM & DMW \\
\hline Fin14 & $92.7 \%$ & $92.7 \%$ & $92.7 \%$ & $8.5 \%$ & $7.2 \%$ & $-26.8 \%$ & $15.4 \%$ & $4.1 \%$ & $4.1 \%$ \\
\hline Han004 & $4.8 \%$ & $4.0 \%$ & $5.6 \%$ & $6.8 \%$ & $0.0 \%$ & $-35.0 \%$ & $-0.6 \%$ & $29.5 \%$ & $35.7 \%$ \\
\hline Han005 & $6.5 \%$ & $5.4 \%$ & $7.5 \%$ & $11.7 \%$ & $-0.9 \%$ & $-62.5 \%$ & $-2.0 \%$ & $41.4 \%$ & $47.2 \%$ \\
\hline KLN06 & $-29.6 \%$ & $-29.6 \%$ & $-29.6 \%$ & $-11.3 \%$ & $-10.5 \%$ & $-29.8 \%$ & $-15.8 \%$ & $-28.0 \%$ & $-28.4 \%$ \\
\hline KLN07 & $4.2 \%$ & $4.2 \%$ & $4.2 \%$ & $3.1 \%$ & $3.3 \%$ & $-24.6 \%$ & $-4.2 \%$ & $-20.9 \%$ & $-21.7 \%$ \\
\hline KLN08 & $26.7 \%$ & $26.7 \%$ & $26.7 \%$ & $2.0 \%$ & $-0.1 \%$ & $-34.9 \%$ & $-8.8 \%$ & $-27.5 \%$ & $-29.0 \%$ \\
\hline KLN09 & $-23.0 \%$ & $-23.5 \%$ & $-17.5 \%$ & $-10.2 \%$ & $-8.3 \%$ & $-29.2 \%$ & $-10.8 \%$ & $-29.7 \%$ & $-29.2 \%$ \\
\hline KLN10 & $-1.1 \%$ & $-1.5 \%$ & $4.0 \%$ & $-7.3 \%$ & $-8.0 \%$ & $-33.5 \%$ & $-10.7 \%$ & $-34.7 \%$ & $-34.4 \%$ \\
\hline KLN11 & $41.3 \%$ & $40.9 \%$ & $46.3 \%$ & $2.2 \%$ & $-1.7 \%$ & $-29.5 \%$ & $-4.6 \%$ & $-31.9 \%$ & $-32.0 \%$ \\
\hline KLN12 & $-35.7 \%$ & $-36.2 \%$ & $-29.6 \%$ & $-15.6 \%$ & $-13.2 \%$ & $-24.9 \%$ & $-14.2 \%$ & $-29.6 \%$ & $-28.8 \%$ \\
\hline KLN13 & $-34.2 \%$ & $-34.6 \%$ & $-28.1 \%$ & $-17.7 \%$ & $-17.1 \%$ & $-30.0 \%$ & $-17.7 \%$ & $-38.3 \%$ & $-37.3 \%$ \\
\hline KLN14 & $11.3 \%$ & $10.8 \%$ & $17.0 \%$ & $-8.2 \%$ & $-14.6 \%$ & $-21.3 \%$ & $-14.2 \%$ & $-41.4 \%$ & $-40.6 \%$ \\
\hline KLU001 & $42.6 \%$ & $45.9 \%$ & $53.6 \%$ & $26.8 \%$ & $23.4 \%$ & $19.5 \%$ & $23.4 \%$ & $19.8 \%$ & $19.8 \%$ \\
\hline SaL02 & $-5.7 \%$ & $-4.1 \%$ & $0.7 \%$ & $-2.0 \%$ & $-1.7 \%$ & $131.9 \%$ & $-1.7 \%$ & $-11.2 \%$ & $-8.5 \%$ \\
\hline SaL03 & $16.3 \%$ & $18.1 \%$ & $23.8 \%$ & $-2.6 \%$ & $0.5 \%$ & $255.4 \%$ & $-0.7 \%$ & $-5.6 \%$ & $-2.7 \%$ \\
\hline SaL04 & $40.1 \%$ & $42.4 \%$ & $49.3 \%$ & $-9.1 \%$ & $-5.2 \%$ & $381.1 \%$ & $-7.3 \%$ & $0.3 \%$ & $2.7 \%$ \\
\hline SaL07 & $24.9 \%$ & $24.9 \%$ & $24.9 \%$ & $-10.1 \%$ & $-10.9 \%$ & $-28.1 \%$ & $-8.2 \%$ & $8.0 \%$ & $1.4 \%$ \\
\hline
\end{tabular}

Table 8. Load cases including pressurizing in the AMSD25 data set and the response of reference multiaxial fatigue strength criteria to them.

\begin{tabular}{|c|c|c|c|c|c|c|c|c|c|c|c|c|}
\hline \multirow{2}{*}{ Item } & \multirow{2}{*}{$\begin{array}{c}\sigma_{x a} \\
(\mathrm{MPa})\end{array}$} & \multirow{2}{*}{$\begin{array}{c}\sigma_{x m} \\
(\mathbf{M P a})\end{array}$} & \multirow{2}{*}{$\begin{array}{c}\sigma_{y a} \\
(\mathrm{MPa})\end{array}$} & \multirow{2}{*}{$\begin{array}{c}\sigma_{y m} \\
(\mathrm{MPa})\end{array}$} & \multirow{2}{*}{$\begin{array}{c}\sigma_{z m} \\
(\mathbf{M P a})\end{array}$} & \multirow{2}{*}{$\begin{array}{c}\tau_{x y a} \\
(\mathrm{MPa})\end{array}$} & \multirow{2}{*}{$\delta_{x y}\left(^{\circ}\right)$} & \multirow{2}{*}{$\delta_{y}\left(^{\circ}\right)$} & \multicolumn{4}{|c|}{$\Delta F I(\%)$} \\
\hline & & & & & & & & & $\mathrm{PCN}$ & PIN & MMP & DV \\
\hline FF057 & 0.0 & 241.9 & 0.0 & 18.2 & 0.0 & 146.5 & 0 & 0 & $1.9 \%$ & $8.2 \%$ & $5.2 \%$ & $16.4 \%$ \\
\hline FF059 & 0.0 & 227.5 & 0.0 & -19.5 & -40.0 & 171.8 & 0 & 0 & $13.1 \%$ & $12.0 \%$ & $16.3 \%$ & $20.9 \%$ \\
\hline
\end{tabular}


Table 8. Cont.

\begin{tabular}{|c|c|c|c|c|c|c|c|c|c|c|c|c|}
\hline \multirow{2}{*}{ Item } & \multirow{2}{*}{$\begin{array}{c}\sigma_{x a} \\
(\mathrm{MPa})\end{array}$} & \multirow{2}{*}{$\begin{array}{c}\sigma_{x m} \\
(\mathrm{MPa})\end{array}$} & \multirow{2}{*}{$\begin{array}{c}\sigma_{y a} \\
(\mathrm{MPa})\end{array}$} & \multirow{2}{*}{$\begin{array}{c}\sigma_{y m} \\
(\mathbf{M P a})\end{array}$} & \multirow{2}{*}{$\begin{array}{c}\sigma_{z m} \\
(\mathrm{MPa})\end{array}$} & \multirow{2}{*}{$\begin{array}{c}\tau_{x y a} \\
(\mathrm{MPa})\end{array}$} & \multirow{2}{*}{$\delta_{x y}\left(^{\circ}\right)$} & \multirow{2}{*}{$\delta_{y}\left(^{\circ}\right)$} & \multicolumn{4}{|c|}{$\Delta F I(\%)$} \\
\hline & & & & & & & & & PCN & PIN & MMP & DV \\
\hline Mie06 & 261.0 & 170.0 & 261.0 & 340.0 & 0.0 & 0.0 & 0 & 0 & $-6.7 \%$ & $21.1 \%$ & $-14.6 \%$ & $34.5 \%$ \\
\hline Mie07 & 275.0 & 170.0 & 275.0 & 340.0 & 0.0 & 0.0 & 0 & 60 & $3.8 \%$ & $23.2 \%$ & $-10.8 \%$ & $31.0 \%$ \\
\hline Mie08 & 240.0 & 170.0 & 240.0 & 340.0 & 0.0 & 0.0 & 0 & 90 & $4.2 \%$ & $15.2 \%$ & $-20.3 \%$ & $16.8 \%$ \\
\hline SiB008 & 335.2 & 0.0 & 368.7 & 368.7 & 0.0 & 0.0 & 0 & 0 & $1.6 \%$ & $27.1 \%$ & $-10.0 \%$ & $32.7 \%$ \\
\hline SiB009 & 309.7 & 309.7 & 340.6 & 340.6 & 0.0 & 0.0 & 0 & 0 & $-3.4 \%$ & $25.6 \%$ & $-9.2 \%$ & $42.3 \%$ \\
\hline SiB010 & 301.1 & 301.1 & 331.2 & 331.2 & 0.0 & 0.0 & 0 & 90 & $8.9 \%$ & $21.7 \%$ & $-11.7 \%$ & $25.8 \%$ \\
\hline TAK10 & 223.6 & 255.0 & 167.7 & 210.8 & 0.0 & 111.8 & 90 & 180 & $5.1 \%$ & $9.3 \%$ & $-13.8 \%$ & $24.8 \%$ \\
\hline
\end{tabular}

Table 9. The response of the new multiaxial fatigue strength criteria evaluated to load cases from the AMSD25 data set including pressurizing. The void cells mark the load cases, which the criteria are not able to process.

\begin{tabular}{|c|c|c|c|c|c|c|c|c|c|}
\hline \multirow{3}{*}{ Item } & \multicolumn{9}{|c|}{$\Delta F I(\%)$} \\
\hline & \multicolumn{3}{|c|}{ KP } & \multirow{2}{*}{ WS } & \multirow{2}{*}{ Böhme } & \multirow{2}{*}{ MDC } & \multirow{2}{*}{ M3HW } & \multicolumn{2}{|c|}{ Yankin } \\
\hline & NK & OP & GP & & & & & VM & DMW \\
\hline FF057 & $5.9 \%$ & $5.9 \%$ & $5.9 \%$ & & $8.6 \%$ & & $12.6 \%$ & $7.9 \%$ & $7.9 \%$ \\
\hline FF059 & & & & & $20.9 \%$ & & $27.1 \%$ & $16.9 \%$ & $16.9 \%$ \\
\hline Mie06 & $17.1 \%$ & $4.9 \%$ & $28.6 \%$ & & $15.6 \%$ & & $15.7 \%$ & $-2.5 \%$ & $8.6 \%$ \\
\hline Mie07 & $35.9 \%$ & $30.5 \%$ & $41.0 \%$ & & $20.7 \%$ & & $-0.8 \%$ & $-9.4 \%$ & $1.5 \%$ \\
\hline Mie08 & $21.2 \%$ & $21.2 \%$ & $21.2 \%$ & & $9.8 \%$ & & $-17.2 \%$ & $-2.7 \%$ & $8.8 \%$ \\
\hline SiB008 & $30.9 \%$ & $17.2 \%$ & $41.4 \%$ & & $27.1 \%$ & & $29.9 \%$ & $9.2 \%$ & $14.4 \%$ \\
\hline SiB009 & $27.4 \%$ & $14.0 \%$ & $37.6 \%$ & & $23.5 \%$ & & $20.0 \%$ & $0.0 \%$ & $13.6 \%$ \\
\hline SiB010 & $36.5 \%$ & $37.6 \%$ & $35.8 \%$ & & $21.0 \%$ & & $-7.8 \%$ & $3.2 \%$ & $17.0 \%$ \\
\hline TAK10 & $9.1 \%$ & $19.9 \%$ & $-1.0 \%$ & & $7.6 \%$ & & $-3.2 \%$ & $-6.7 \%$ & $4.7 \%$ \\
\hline
\end{tabular}

In addition to these results, the $\Delta F I$ statistics were gathered in Table 10 for the entire FatLim set comprising 284 items, for the AMSD25 data set and for several more selections from FatLim. Evaluation on these groups is enforced by the inability of specific criteria either to work with particular data inputs or by the unavailability of specific material parameters necessary for their computation. These limited data sets are:

- $\quad\{\mathrm{KP}\}-272$ items. No load cases including the third normal stress are involved.

- $\quad\{W S\}-224$ items: Only the combination of axial and torsion load channels is accepted.

- $\quad\{$ MDC -167 items: Only load cases for which the Basquin curve description was available are involved, thus setting aside any results from staircase experiments.

- $\quad\{Y\}-80$ items: Only load cases for which the $R_{m t}$ value is available from experiments.

Table 10. Summary of the $\Delta F I$ statistics for various configurations of the evaluated benchmark sets.

\begin{tabular}{|c|c|c|c|c|c|c|c|c|c|c|c|c|c|}
\hline \multicolumn{14}{|c|}{$\Delta F I$ statistics for the full fatLim benchmark-284 items } \\
\hline$\Delta F I$ & \multirow{2}{*}{ PCN } & \multirow{2}{*}{ PIN } & \multirow{2}{*}{ MMP } & \multirow{2}{*}{ DV } & \multicolumn{3}{|c|}{ Khalij-Pagnacco } & \multirow{2}{*}{ WS } & \multirow{2}{*}{ Böhme } & \multirow{2}{*}{ MDC } & \multirow{2}{*}{ M3HW } & \multicolumn{2}{|c|}{ Yankin } \\
\hline par. & & & & & NK & $\mathrm{OP}$ & GOU & & & & & VM & DMW \\
\hline Max. & $24.2 \%$ & $28.9 \%$ & $20.3 \%$ & $43.8 \%$ & $249.8 \%$ & $242.6 \%$ & $249.8 \%$ & $166.5 \%$ & $29.5 \%$ & $381.1 \%$ & $51.8 \%$ & $58.2 \%$ & $53.1 \%$ \\
\hline Min. & $-22.4 \%$ & $-15.4 \%$ & $-45.2 \%$ & $-43.6 \%$ & $-39.3 \%$ & $-36.2 \%$ & $-48.2 \%$ & $-45.2 \%$ & $-35.5 \%$ & $-100.0 \%$ & $-35.3 \%$ & $-47.3 \%$ & $-44.3 \%$ \\
\hline Aver. & $1.1 \%$ & $1.9 \%$ & $-5.1 \%$ & $-2.2 \%$ & $11.3 \%$ & $10.0 \%$ & $13.5 \%$ & $1.1 \%$ & $-0.2 \%$ & $22.9 \%$ & $-0.9 \%$ & $-3.3 \%$ & $-2.0 \%$ \\
\hline SD & $6.1 \%$ & $7.2 \%$ & $10.8 \%$ & $15.9 \%$ & $31.2 \%$ & $30.8 \%$ & $31.7 \%$ & $22.7 \%$ & $8.8 \%$ & $73.4 \%$ & $12.7 \%$ & $14.7 \%$ & $13.8 \%$ \\
\hline
\end{tabular}


Table 10. Cont.

$\Delta F I$ statistics for $\{\mathrm{KP}\}$ set-272 items without cases including the third normal stress channel

\begin{tabular}{|c|c|c|c|c|c|c|c|c|c|c|c|c|c|}
\hline$\Delta F I$ & \multirow{2}{*}{$\mathrm{PCN}$} & \multirow{2}{*}{ PIN } & \multirow{2}{*}{ MMP } & \multirow{2}{*}{ DV } & \multicolumn{3}{|c|}{ Khalij-Pagnacco } & \multirow{2}{*}{ WS } & \multirow{2}{*}{ Böhme } & \multirow{2}{*}{ MDC } & \multirow{2}{*}{ M3HW - } & \multicolumn{2}{|c|}{ Yankin } \\
\hline par. & & & & & NK & OP & GOU & & & & & VM & DMW \\
\hline Max. & $22.5 \%$ & $28.9 \%$ & $20.3 \%$ & $43.8 \%$ & $249.8 \%$ & $242.6 \%$ & $249.8 \%$ & $166.5 \%$ & $29.5 \%$ & $381.1 \%$ & $51.8 \%$ & $58.2 \%$ & $53.1 \%$ \\
\hline Min. & $-22.4 \%$ & $-15.4 \%$ & $-45.2 \%$ & $-43.6 \%$ & $-39.3 \%$ & $-36.2 \%$ & $-48.2 \%$ & $-45.2 \%$ & $-35.5 \%$ & $-100.0 \%$ & $-35.3 \%$ & $-47.3 \%$ & $-44.3 \%$ \\
\hline Aver. & $0.8 \%$ & $1.5 \%$ & $-5.1 \%$ & $-2.5 \%$ & $11.3 \%$ & $10.0 \%$ & $13.5 \%$ & $1.1 \%$ & $-0.7 \%$ & $22.9 \%$ & $-1.2 \%$ & $-3.3 \%$ & $-2.3 \%$ \\
\hline $\mathrm{SD}$ & $5.8 \%$ & $7.0 \%$ & $10.7 \%$ & $16.1 \%$ & $31.2 \%$ & $30.8 \%$ & $31.7 \%$ & $22.7 \%$ & $8.4 \%$ & $73.4 \%$ & $12.4 \%$ & $14.5 \%$ & $13.8 \%$ \\
\hline
\end{tabular}

$\triangle F I$ statistics for $\{\mathrm{WS}\}$ set-224 items of axial and torsion loading only

\begin{tabular}{|c|c|c|c|c|c|c|c|c|c|c|c|c|c|}
\hline$\Delta F I$ & \multirow{2}{*}{ PCN } & \multirow{2}{*}{ PIN } & \multirow{2}{*}{ MMP } & \multirow{2}{*}{ DV } & \multicolumn{3}{|c|}{ Khalij-Pagnacco } & \multirow{2}{*}{ WS } & \multirow{2}{*}{ Böhme } & \multirow{2}{*}{$\mathrm{MDC}$} & \multirow{2}{*}{ M3HW - } & \multicolumn{2}{|c|}{ Yankin } \\
\hline par. & & & & & NK & $\mathrm{OP}$ & GOU & & & & & VM & DMW \\
\hline Max. & $22.5 \%$ & $28.9 \%$ & $20.3 \%$ & $43.8 \%$ & $249.8 \%$ & $242.6 \%$ & $249.8 \%$ & $166.5 \%$ & $29.5 \%$ & $381.1 \%$ & $51.8 \%$ & $58.2 \%$ & $53.1 \%$ \\
\hline Min. & $-22.4 \%$ & $-15.4 \%$ & $-40.2 \%$ & $-43.6 \%$ & $-35.7 \%$ & $-36.2 \%$ & $-29.6 \%$ & $-45.2 \%$ & $-35.5 \%$ & $-100.0 \%$ & $-35.3 \%$ & $-47.3 \%$ & $-44.3 \%$ \\
\hline Aver. & $0.9 \%$ & $0.3 \%$ & $-3.6 \%$ & $-5.3 \%$ & $12.2 \%$ & $10.9 \%$ & $14.6 \%$ & $1.4 \%$ & $-1.5 \%$ & $22.9 \%$ & $-1.5 \%$ & $-3.7 \%$ & $-3.4 \%$ \\
\hline SD & $6.1 \%$ & $6.0 \%$ & $10.0 \%$ & $14.7 \%$ & $33.4 \%$ & $33.2 \%$ & $33.6 \%$ & $22.8 \%$ & $7.7 \%$ & $73.4 \%$ & $12.2 \%$ & $15.1 \%$ & $14.4 \%$ \\
\hline \multicolumn{14}{|c|}{$\Delta F I$ statistics for $\{\mathrm{MDC}\}$ set-167 items including the description of relevant Basquin curves } \\
\hline$\Delta F I$ & \multirow{2}{*}{ PCN } & \multirow{2}{*}{ PIN } & \multirow{2}{*}{ MMP } & \multirow{2}{*}{ DV } & \multicolumn{3}{|c|}{ Khalij-Pagnacco } & \multirow{2}{*}{ WS } & \multirow{2}{*}{ Böhme } & \multirow{2}{*}{ MDC } & \multirow{2}{*}{$\mathrm{M} 3 \mathrm{HW}$} & \multicolumn{2}{|c|}{ Yankin } \\
\hline par. & & & & & NK & $\mathrm{OP}$ & GOU & & & & & $\mathrm{VM}$ & DMW \\
\hline Max. & $22.5 \%$ & $28.9 \%$ & $20.3 \%$ & $43.8 \%$ & $249.8 \%$ & $242.6 \%$ & $249.8 \%$ & $166.5 \%$ & $29.5 \%$ & $381.1 \%$ & $51.8 \%$ & $58.2 \%$ & $53.1 \%$ \\
\hline Min. & $-15.4 \%$ & $-15.4 \%$ & $-40.2 \%$ & $-43.6 \%$ & $-35.7 \%$ & $-36.2 \%$ & $-29.6 \%$ & $-45.2 \%$ & $-35.5 \%$ & $-100.0 \%$ & $-35.3 \%$ & $-41.4 \%$ & $-40.6 \%$ \\
\hline Aver. & $0.9 \%$ & $0.0 \%$ & $-4.4 \%$ & $-4.1 \%$ & $12.1 \%$ & $10.9 \%$ & $14.2 \%$ & $1.8 \%$ & $-1.6 \%$ & $22.9 \%$ & $-0.7 \%$ & $-2.4 \%$ & $-2.3 \%$ \\
\hline SD & $6.0 \%$ & $5.8 \%$ & $10.5 \%$ & $14.9 \%$ & $32.2 \%$ & $32.0 \%$ & $32.4 \%$ & $24.4 \%$ & $7.7 \%$ & $73.4 \%$ & $12.0 \%$ & $15.1 \%$ & $14.9 \%$ \\
\hline
\end{tabular}

$\Delta F I$ statistics for $\{\mathrm{Y}\}$ set-80 items with the experimentally-set values of ultimate shear strength

\begin{tabular}{|c|c|c|c|c|c|c|c|c|c|c|c|c|}
\hline \multirow{2}{*}{$\begin{array}{l}\Delta F I \\
\text { par. }\end{array}$} & \multirow{2}{*}{$\mathrm{PCN}$} & \multirow{2}{*}{ PIN } & \multirow{2}{*}{ MMP } & \multirow{2}{*}{ DV } & \multicolumn{3}{|c|}{ Khalij-Pagnacco } & \multirow{2}{*}{ WS } & \multirow{2}{*}{ Böhme } & \multirow{2}{*}{ MDC } & \multirow{2}{*}{ M3HW } & \multirow[t]{2}{*}{ Yankin } \\
\hline & & & & & NK & OP & GOU & & & & & \\
\hline Max. & $22.5 \%$ & $15.8 \%$ & $16.3 \%$ & $20.9 \%$ & $191.3 \%$ & $187.1 \%$ & $193.3 \%$ & $84.7 \%$ & $20.9 \%$ & $350.4 \%$ & $27.1 \%$ & $34.6 \%$ \\
\hline Min. & $-11.4 \%$ & $-14.1 \%$ & $-40.2 \%$ & $-43.6 \%$ & $-24.0 \%$ & $-24.7 \%$ & $-24.0 \%$ & $-45.2 \%$ & $-20.4 \%$ & $-100.0 \%$ & $-35.3 \%$ & $-32.6 \%$ \\
\hline Aver. & $1.6 \%$ & $0.9 \%$ & $-5.3 \%$ & $-3.2 \%$ & $13.0 \%$ & $11.5 \%$ & $14.6 \%$ & $3.4 \%$ & $-0.7 \%$ & $48.5 \%$ & $1.6 \%$ & $-0.7 \%$ \\
\hline SD & $6.1 \%$ & $5.3 \%$ & $9.2 \%$ & $13.9 \%$ & $32.5 \%$ & $32.3 \%$ & $32.7 \%$ & $26.6 \%$ & $7.9 \%$ & $92.0 \%$ & $11.7 \%$ & $12.2 \%$ \\
\hline
\end{tabular}

$\triangle F I$ statistics for AMSD25 set- 57 items

\begin{tabular}{|c|c|c|c|c|c|c|c|c|c|c|c|c|c|}
\hline$\Delta F I$ & \multirow{2}{*}{$\mathrm{PCN}$} & \multirow{2}{*}{ PIN } & \multirow{2}{*}{ MMP } & \multirow{2}{*}{ DV } & \multicolumn{3}{|c|}{ Khalij-Pagnacco } & \multirow{2}{*}{ WS } & \multirow{2}{*}{ Böhme } & \multirow{2}{*}{ MDC } & \multirow{2}{*}{ M3HW } & \multicolumn{2}{|c|}{ Yankin } \\
\hline par. & & & & & NK & OP & GOU & & & & & VM & DMW \\
\hline Max. & $22.5 \%$ & $28.9 \%$ & $20.3 \%$ & $43.8 \%$ & $249.8 \%$ & $242.6 \%$ & $249.8 \%$ & $166.5 \%$ & $27.1 \%$ & $381.1 \%$ & $51.8 \%$ & $58.2 \%$ & $53.1 \%$ \\
\hline Min. & $-22.4 \%$ & $-15.4 \%$ & $-40.2 \%$ & $-43.6 \%$ & $-35.7 \%$ & $-36.2 \%$ & $-29.6 \%$ & $-45.2 \%$ & $-35.5 \%$ & $-100.0 \%$ & $-33.8 \%$ & $-47.3 \%$ & $-44.3 \%$ \\
\hline Aver. & $0.8 \%$ & $4.2 \%$ & $-8.9 \%$ & $-7.2 \%$ & $31.7 \%$ & $30.6 \%$ & $34.3 \%$ & $12.2 \%$ & $0.1 \%$ & $64.5 \%$ & $3.0 \%$ & $-6.0 \%$ & $-4.3 \%$ \\
\hline SD & $9.0 \%$ & $11.3 \%$ & $14.9 \%$ & $24.8 \%$ & $57.2 \%$ & $56.6 \%$ & $57.4 \%$ & $38.7 \%$ & $13.1 \%$ & $129.4 \%$ & $17.2 \%$ & $23.1 \%$ & $23.2 \%$ \\
\hline
\end{tabular}

Due to these limitations imposed and accepted, the relevant criterion can be fully compared with other criteria only on the data set for which its limitations were applied. Thus, e.g., the KP criterion can be compared to other non-limited data only on the $\{\mathrm{KP}\}$ data set, but, e.g., the MDC criterion, which imposes further limitations, is comparable to the KP criterion only on the $\{\mathrm{MDC}\}$ set.

Because understanding of fatigue performance of individual criteria only from Table 10 can be limited, and the Discussion section refers often to the response of cri- 
teria to the subsets described in the list at the end of Section 2, two additional tables were added. Table 11 refers to the average values of $\Delta F I$ obtained in these subsets, while Table 12 describes the standard deviations of $\Delta F I$ calculated for individual evaluated criteria. Although maximum and minimum values would help to detect anomalous behavior of some criteria in particular conditions, these values are not provided because of the length of the paper. Usually, an abrupt change of the average value, an increased standard deviation, or a combination of both helps to detect such occurrences.

The information delivered within Tables 4-12 is rigorous and comparable with other future attempts; it does not allow the reader, however, to quickly grasp the quality of individual criteria. Because of that, Figure 1 was added. It presents histograms of the fatigue index error for the six newly documented criteria and their versions. Due to the lack of space, histograms for the reference criteria are not provided.

Table 11. Summary of the $\Delta F I$ averages obtained for individual criteria and for various subgroups of FatLim.

\begin{tabular}{|c|c|c|c|c|c|c|c|c|c|c|c|c|c|}
\hline \multirow{2}{*}{$\begin{array}{c}\Delta F I \\
\text { Subset }\end{array}$} & \multirow{2}{*}{ PCN } & \multirow{2}{*}{ PIN } & \multirow{2}{*}{ MMP } & \multirow{2}{*}{$\mathrm{V}$} & \multicolumn{3}{|c|}{ Khalij-Pagnacco } & \multirow{2}{*}{ WS } & \multirow{2}{*}{ Böhme } & \multirow{2}{*}{ MDC } & \multirow{2}{*}{ M3HW- } & \multicolumn{2}{|c|}{ Yankin } \\
\hline & & & & & NK & OP & GOU & & & & & VM & DMW \\
\hline $\mathrm{Ax}$ & 0.010 & $3.1 \%$ & $-0.9 \%$ & & $36.9 \%$ & $36.1 \%$ & $39.4 \%$ & $13.7 \%$ & & & $3.8 \%$ & $-4.9 \%$ & $-2.8 \%$ \\
\hline To & $-1.6 \%$ & $-2.1 \%$ & $-17.4 \%$ & $-17.4 \%$ & $13.5 \%$ & $13.5 \%$ & $13.5 \%$ & $-1.5 \%$ & $-2.0 \%$ & $-17.7 \%$ & $2.0 \%$ & $-3.7 \%$ & $-6.8 \%$ \\
\hline MS & $0.9 \%$ & $2.7 \%$ & $-7.7 \%$ & $-2.3 \%$ & $13.0 \%$ & $11.9 \%$ & $14.9 \%$ & $4.9 \%$ & $0.0 \%$ & $33.2 \%$ & $1.5 \%$ & $-3.2 \%$ & $-1.4 \%$ \\
\hline MS- & $2.1 \%$ & $6.3 \%$ & $-6.1 \%$ & $-3.0 \%$ & $6.3 \%$ & $7.7 \%$ & $7.0 \%$ & $4.1 \%$ & $1.8 \%$ & $38.4 \%$ & $8.5^{\circ}$ & $8.4 \%$ & $8.3 \%$ \\
\hline nMS & $1.6 \%$ & $0.2 \%$ & $0.8 \%$ & $-2.0 \%$ & $7.7 \%$ & $6.1 \%$ & $10.7 \%$ & $-5.1 \%$ & $-0.6 \%$ & $3.6 \%$ & $-6.1 \%$ & $-3.3 \%$ & $-3.3 \%$ \\
\hline $\mathrm{NP}$ & $1.7 \%$ & $3.5 \%$ & $-4.9 \%$ & $-3.5 \%$ & $7.9 \%$ & $7.4 \%$ & $9.1 \%$ & $4.0 \%$ & $0.7 \%$ & $64.4 \%$ & $-3.4 \%$ & $-4.4 \%$ & $-2.6 \%$ \\
\hline IP & $1.6 \%$ & $0.3 \%$ & $-4.5 \%$ & $3.0 \%$ & $4.9 \%$ & $2.2 \%$ & $8.4 \%$ & -0.210 & $-0.3 \%$ & $0.2 \%$ & $-0.2 \%$ & $-1.1 \%$ & $0.0 \%$ \\
\hline $\begin{array}{c}\text { IP, } \\
\text { nMS }\end{array}$ & $2.7 \%$ & $-0.1 \%$ & $-0.7 \%$ & $4.2 \%$ & $5.5 \%$ & $3.6 \%$ & $8.2 \%$ & $-5.9 \%$ & $-0.3 \%$ & $4.0 \%$ & $-0.3 \%$ & $2.1 \%$ & $2.1 \%$ \\
\hline OOP & $0.0 \%$ & $3.2 \%$ & $-6.6 \%$ & $-6.5 \%$ & $9.0 \%$ & $0.5 \%$ & $10.9 \%$ & $-0.9 \%$ & $-1.0 \%$ & $3.5 \%$ & $-11.5 \%$ & $-11.7 \%$ & $-8.5 \%$ \\
\hline $\begin{array}{l}\text { OOP, } \\
\text { nMS }\end{array}$ & $0.7 \%$ & $1.0 \%$ & $3.8 \%$ & $-14.4 \%$ & $12.3 \%$ & $11.1 \%$ & $15.6 \%$ & $-3.5 \%$ & $-1.2 \%$ & $2.7 \%$ & $-17.8 \%$ & $-14.3 \%$ & -14.3 \\
\hline
\end{tabular}

Table 12. Summary of standard deviations of the $\triangle F I$ obtained for individual criteria and for various subgroups of FatLim.

\begin{tabular}{|c|c|c|c|c|c|c|c|c|c|c|c|c|c|}
\hline \multirow{2}{*}{$\frac{\Delta F I}{\text { Subset }}$} & \multirow{2}{*}{ PCN } & \multirow{2}{*}{ PIN } & \multirow{2}{*}{ MMP } & \multirow{2}{*}{ DV } & \multicolumn{3}{|c|}{ Khalij-Pagnacco } & \multirow{2}{*}{ WS } & \multirow{2}{*}{ Böhme } & \multirow{2}{*}{ MDC } & \multirow{2}{*}{ M3HW } & \multicolumn{2}{|c|}{ Yankin } \\
\hline & & & & & NK & OP & GOU & & & & & VM & DMW \\
\hline$A x$ & $5.8 \%$ & $6.8 \%$ & $8.3 \%$ & $17.5 \%$ & $64.8 \%$ & $63.5 \%$ & $65.0 \%$ & $33.6 \%$ & $9.0 \%$ & $90.7 \%$ & $13.1 \%$ & $19.8 \%$ & $19.2 \%$ \\
\hline To & $5.1 \%$ & $5.6 \%$ & $12.1 \%$ & $12.1 \%$ & $33.0 \%$ & $33.0 \%$ & $33.0 \%$ & $5.2 \%$ & $5.2 \%$ & $12.3 \%$ & $11.2 \%$ & $12.4 \%$ & $11.4 \%$ \\
\hline MS & $6.4 \%$ & $7.7 \%$ & $11.0 \%$ & $17.8 \%$ & $36.8 \%$ & $36.1 \%$ & $37.3 \%$ & $26.4 \%$ & $9.5 \%$ & $88.7 \%$ & $12.7 \%$ & $16.3 \%$ & $15.2 \%$ \\
\hline MS- & $9.9 \%$ & $7.3 \%$ & $12.8 \%$ & $14.9 \%$ & $16.0 \%$ & $15.8 \%$ & $16.7 \%$ & $16.8 \%$ & $13.2 \%$ & $55.8 \%$ & $13.7 \%$ & $17.7 \%$ & $14.3 \%$ \\
\hline nMS & $5.4 \%$ & $5.6 \%$ & $7.6 \%$ & $10.8 \%$ & $12.5 \%$ & $13.5 \%$ & $13.2 \%$ & $12.7 \%$ & $7.1 \%$ & $12.6 \%$ & $11.0 \%$ & $10.0 \%$ & $10.0 \%$ \\
\hline NP & $7.1 \%$ & $6.6 \%$ & $12.0 \%$ & $16.1 \%$ & $16.7 \%$ & $16.2 \%$ & $18.1 \%$ & $25.9 \%$ & $9.8 \%$ & $99.7 \%$ & $15.1 \%$ & $15.4 \%$ & $14.0 \%$ \\
\hline IP & $4.6 \%$ & $7.7 \%$ & $7.8 \%$ & $13.2 \%$ & $12.9 \%$ & $12.7 \%$ & $13.5 \%$ & $10.0 \%$ & $7.9 \%$ & $10.8 \%$ & $7.9 \%$ & $11.2 \%$ & $11.0 \%$ \\
\hline $\begin{array}{c}\text { IP, } \\
\text { nMS }\end{array}$ & $3.9 \%$ & $5.7 \%$ & $5.7 \%$ & $4.9 \%$ & $8.8 \%$ & $9.7 \%$ & $9.5 \%$ & $11.3 \%$ & $6.2 \%$ & $6.1 \%$ & $6.2 \%$ & $5.0 \%$ & $5.0 \%$ \\
\hline OOP & $6.0 \%$ & $7.0 \%$ & $13.6 \%$ & $17.5 \%$ & $18.3 \%$ & $17.6 \%$ & $20.1 \%$ & $14.8 \%$ & $10.3 \%$ & $25.3 \%$ & $12.6 \%$ & $13.3 \%$ & $12.8 \%$ \\
\hline $\begin{array}{l}\text { OOP, } \\
\text { nMS }\end{array}$ & $7.1 \%$ & $5.5 \%$ & $9.9 \%$ & $8.5 \%$ & $16.8 \%$ & $18.0 \%$ & $17.5 \%$ & $15.0 \%$ & $8.4 \%$ & $21.9 \%$ & $9.0 \%$ & $8.6 \%$ & $8.6 \%$ \\
\hline
\end{tabular}



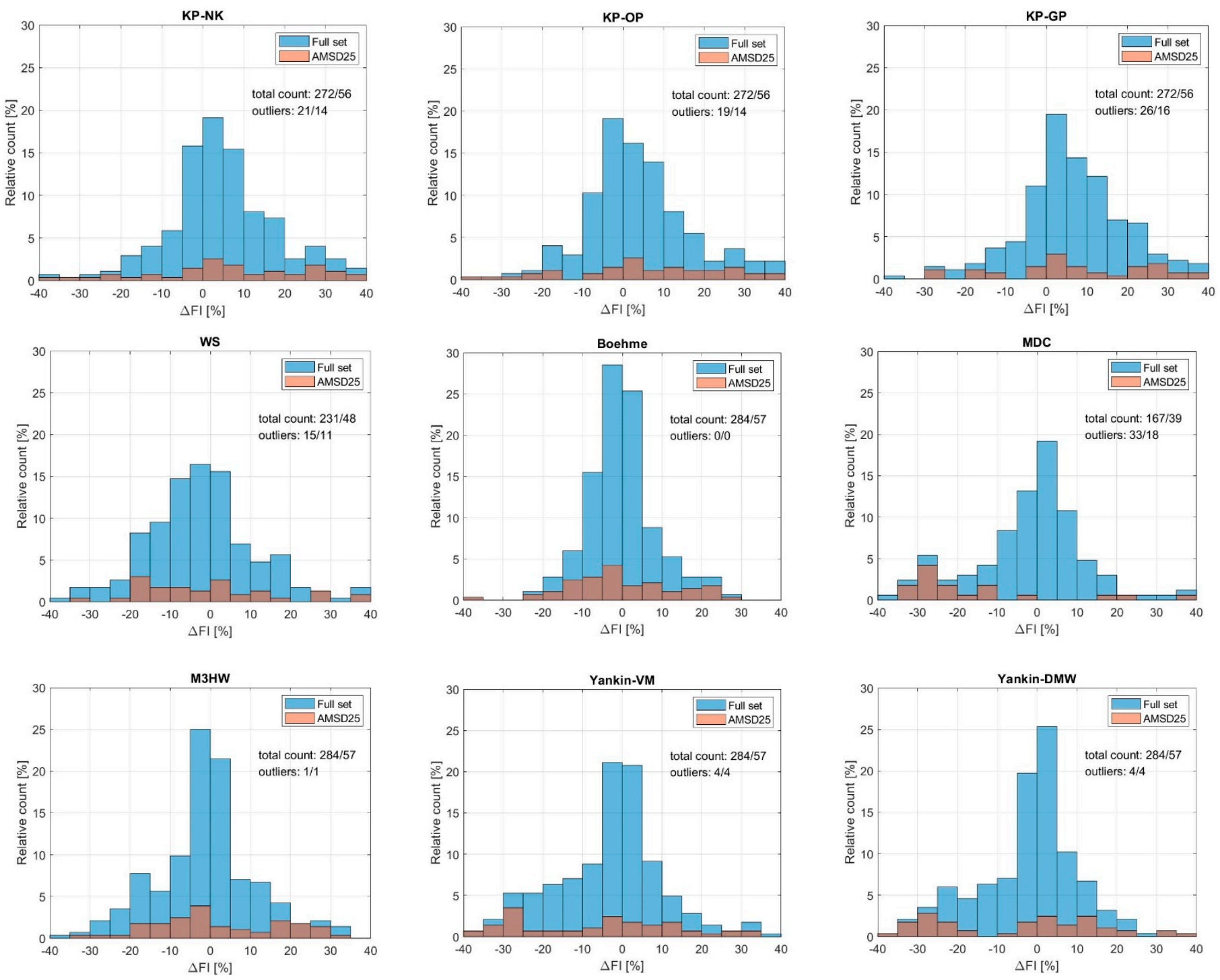

Figure 1. Histograms of $\Delta F I$ occurrence in the FatLim full set (blue) and in the AMSD25 subset (salmon). The total count numbers refer to the number of items in each of those test sets, on which the criterion could be applied. The number of outliers describes how many more items would be depicted in the histogram if its whole range could be shown. The relative count refers to the total count of items to which the criterion was applicable and not to the entire FatLim.

\section{Discussion}

\subsection{KP Criterion}

The results of the Khalij and Pagnacco criterion, which extends the Gough-Pollard solution (and Nishihara-Kawamoto solution in the specific NK variant), are not persuasive for using the method in any of the current three formulations. One of the issues is the inappropriate response to purely axial $\{\mathrm{Ax}\}$ and to purely torsion $\{\mathrm{To}\}$ load cases (which are invariably connected to non-zero mean stresses). In tension it concerns three load cases with very high mean tensile stresses (load ratio $R>0.5$ ) or with significant compressive stresses $(R=-4)$. These are relatively extreme cases (and this is the reason why they project into AMSD25), but other criteria master them relatively better. The same tendency in providing extreme outliers in quality of predicted values for high mean stresses (above $R>0.5$ ) is also observed in torsion. 
This behavior is interesting because KP criterion belongs to those material properties derived from four fatigue strengths, i.e., including the cases of repeated loading $s_{0}$ and $t_{0}$. For these load cases, the criterion should provide perfect results if the material parameters are set right. However, its response to higher mean stresses fails. Surprising is the finding that all KP variants provide identical results for the pure torsion load cases. This means that the expected difference in a parameter definition (Equations (6)-(8)) does not occur at all. The reason is simple-all addends, including it, in Equation (4) are zero in such a case. The condition for which $a_{O P}$ was derived (projection of the pure torsion load case to the principal plane) is not applied. Attempts to apply a similar transformation of the stress state to principal stresses, for which is then $\Delta F I$ calculated, show that the criterion in the form in Equation (4) is not independent of the coordinate system and that extremely different results can be obtained for the same stress state if transferred to different coordinate systems.

If the KP criterion provides the correct output for $t_{0}$ case as expected, the more critical is the $s_{0}$ case of the repeated axial loading. Khalij and Pagnacco decided to implement the mean stress effect as proposed within the Liu and Zenner criterion, in its analytical formulation derived for the plane stress state [37]. The formulation there and in [36] differs. Khalij and Pagnacco, in a personal communication, admitted that an error was induced in the transcription into their paper. It should be noted, however, that there are multiple other works by Liu or Zenner [14,55] and the formulation of these parameters is changing in many of them. None of our attempts rectified the response to the $s_{0}$ case, though various alternative setups of the mean stress effect were checked. It must be doubted whether mixing of parts of various criteria without modifying their parameters accordingly is possible. The formulations regarding the normal stresses in both criteria differ quite substantially. The Liu-Zenner solution in the analytical formulation for the repeated load case $\left(\sigma_{x, a}=s_{0} / 2, \sigma_{y, a}=\tau_{x y, a}=0\right)$ results in $s_{0}^{2} / 4$ term only in the amplitude part of the equivalent stress. If the same check is performed for the KP criterion (i.e., without the part concerning the mean stresses), Equation (4) in the amplitude part reduces to $\alpha s_{0}^{2} / 4+(1-\alpha) s_{0} s_{-1}$. It is obvious that if the authors of [36] attempted to connect to these two different formulations the same part describing the mean stress effect, the output cannot coincide. To obtain the correct output for the $\mathrm{KP}$ criterion, the relevant material parameters in the mean stress part $b \cdot \sigma_{m, B}+c \cdot \sigma_{m, C}$ would have to be derived accordingly to the amplitude part definition, which is not the case.

The insufficient response to load cases including mean stresses also projects into the calculation response to the multiaxial load cases. If the load cases without any mean stress are evaluated (which because of the possibilities to mechanically exert loading corresponds only to axial-torsion combination), the quality of results gets closer to other criteria. There are still some cases that cause a worsening of the statistical output. The analysis of the full FatLim table shows that this worsened output concerns cases where the stress on any channel exceeds approximately $85 \%$ of the relevant fatigue strength (e.g., the shear stress amplitude compared to the shear fatigue strength) -in such cases the criterion tends to be too conservative (irrespective of the variant of $a$ parameter definition). The worst two \{nMS\} cases (the response to load cases AR1004 and KLU001) as regards the prediction quality of the KP criterion are contained within the AMSD25 data set. Many others with $\triangle F I$ by only $5-10 \%$ lower are not in AMSD25, however, which means that the worse response to such load cases is specific only to the KP criterion.

It should be noted that for a representative comparison of the prediction quality of the $\mathrm{KP}$ criterion with other new criteria if accepting its intrinsic limitation to plane stress cases, the statistics relevant for the $\{K P\}$ set should be used in Table 10. 


\subsection{WS Criterion}

It was already noted in Section 2.2.2 that one of the issues of this criterion is its limited applicability to axial-torsion load cases only. If only this group of test cases is analyzed (see the response to $\{\mathrm{WS}\}$ set in Table 10) the overall results are better than those of the KP criterion, but they are obviously inferior to other methods that perform better. Analysis of individual test groups shows that while the pure torsion cases are evaluated quite well, the pure axial load cases tend to be extremely conservative for high load ratios. This output is obtained despite the fact that the WS criterion is a four-parametric criterion. It responds perfectly to repeated tension load case because it is used as one of the inputs for defining the $d_{W}$ parameter. The simple weighted sum of normal stress terms in the damage parameter Equation (10) is not capable of providing better results. This unpleasant property also projects into multiaxial load cases, whenever the mean normal stress is higher.

The analysis of the group of load cases without any mean stress uncovers another interesting trend. The criterion tends to lead to over-conservative results for materials with a fatigue strength ratio $\kappa>1.73$, which are sometimes designated as extra-ductile [26,39]. On the other hand, the trend for $\kappa<1.41$ seems to be opposite, i.e., to tend to non-conservative estimates. If there is no mean stress involved, the criterion reduces to:

$$
\sigma_{e q, W S}=\sqrt{\left(a_{W} C_{a}\right)^{2}+\left(b_{W} N_{a}\right)^{2}},
$$

which is nearly identical to the formulation of the QCP criterion proposed by Papuga and Halama [10]. These authors refer to the mathematical derivation used by Papuga and Růžička in [24] to derive the material parameters of critical plane criteria, and they note that his form of quadratic combination of shear and normal stress amplitudes results in two different sets of material parameters for different values of the fatigue strength ratio $\kappa$, where the border between both sets is at $\kappa=1.41$. The way the critical plane is derived in the WS criterion differs from the QCP solution (which uses the simple maximization of the equivalent stress over all planes), but it seems that the solution which uses parameters provided in Equation (11) need not be complete, because these parameters could be valid only within the range of $1.41<\kappa<1.73$. Such a split in the validity of the material parameters for different domains would certainly affect the quality of the fatigue prediction results. Whether or not this assumption is right, the observed behavior dependent on the fatigue strength ratio value projects both to the in-phase and out-of-phase groups, where thus the WS criterion rates not well enough compared to other methods. This is striking if taking into account, e.g., the simplicity of conditions of the $\{$ IP,nMS $\}$ group of load cases, for which the WS criterion results in the higher standard deviation of $\triangle F I$ than any other criterion from more than 30 evaluated criteria.

The WS criterion is interesting by its specific solution for defining the critical plane. This difference in comparison with other concepts of the critical plane definition should become more obvious for out-of-phase cases above all. To analyze this possible effect but not to get affected by the mentioned dependency of the criterion quality on the fatigue strength ratio $\kappa$, the domains in which the criterion presents some issues had to be eliminated from the set. The final set for the comparison $\{\mathrm{Ax}+\mathrm{To}, \mathrm{OOP}, \mathrm{nMS}, 1.41<\kappa<1.73\}$ derived from FatLim reaches 13 items only. Within them, the mean $\triangle F I$ of the WS criterion is $-8.3 \%$ and the standard deviation of $\Delta F I$ is $7.9 \%$, which are values better than those obtained by the Dang Van method or other new criteria except of Böhme (mean $\Delta F I=5.4 \%$, S.D. $(\triangle F I)=6.7 \%)$, but worse than PCN, which does not present this significant shift from zero $\Delta F I$ (mean $\Delta F I=-0.8 \%, \mathrm{SD}(\Delta F I)=7.3 \%$ ). It can be concluded that the modified definition of the critical plane does not bring a substantial enough improvement. 


\subsection{Böhme Criterion}

This criterion is the best performing solution among the newly evaluated criteria tested here. If a detailed analysis is performed, some issues can be discovered, however. While the response to the mean torsion cases in $\{\mathrm{To}\}$ group is of a standard similar with PIN or PCN, the scatter of the results is substantially increased in the domain of mean normal stresses in $\{\mathrm{Ax}\}$ group. This worsening can be attributed to the response to the two load cases with compressive mean stresses on the cast iron tested by Rausch [56], i.e., in the domain, for which Böhme originally developed his model. The benchmarking done in [46] did not detect this issue, because it focused solely on cases including the shear stress amplitude, whereas the Rausch's tests causing problems here are solely uniaxial. If these two tests are removed, the $\Delta F I$ statistics of the $\{\mathrm{Ax}\}$ group improves to values achieved by PIN or PCN.

The potential relationship between too non-conservative response of the criterion in relation to the negative mean normal stress and to brittle materials is confirmed in the observation of the $\{\mathrm{MS}-\}$ group, where a similar trend is found for data from Cengiz [57] and Heidenreich et al. [58] on cast irons.

Because, among the criteria evaluated here, the Böhme criterion is comparable only to the PIN or PCN methods and it surpasses the prediction quality of all newly assessed criteria, these two methods were the main counterpart in the evaluation. In most cases, they provide results of smaller scatter, which can be documented in the $\triangle F I$ statistics. This can also be observed in the reduced $\{\mathrm{IP}, \mathrm{nMS}\}$ and $\{\mathrm{OP}, \mathrm{nMS}\}$ groups where only the equivalent stress without any mean stress effect is compared. It is worth recalling that at that moment the Böhme criterion reduces to the formula identical to the Liu-Zenner method [47].

\subsection{Criterion}

The criterion is formulated as three-parametric, which is likely to affect its prediction quality in comparison to other criteria, which utilize four parameters, two of which are usually related to load states including the mean stress. MDC criterion has no such feature, as the required parameters in addition to $s_{-1}$ and $t_{-1}$ describe again only the response of material to fully reversed loading in the domain of limited lifetime. They reflect in no way the mean stress response.

The mean stress response is thus based on maximum normal stress. Papuga has already commented in [26] that the use of $N_{\max }$ squared for the equivalent stress definition within quadratic QCP or in the Spagnoli criterion [59] tends to provide too conservative estimates for higher load ratios. In the MDC criterion, the response seems to be further worsened by the dependency on material parameters of the Basquin curves in axial and torsion loading. This makes the mean stress effect act oddly, if not even randomly. This issue projects to the $\{\mathrm{MS}\}$ group, with an extreme impact on $\{\mathrm{Ax}\}$ group, which results in $\Delta F I$ values between $-100 \%$ and $381 \%$. Over-conservative results are obtained for the data set from Sauer (SaL, [60]) above all, but even if this data set had been removed, the mean stress response would be too exaggerated. In comparison to this group, $\{$ To $\}$ test group results in statistics closer to many other criteria, though it is far beyond well-ranking criteria.

The noted lower bound $\Delta F I=-100 \%$ concerns the FAD003 load case solely. It can serve as a good illustration of the consequences caused by the selection of the terms in the bracket close to $N_{\max }$ term in Equation (17). The choice of the ratio of fatigue strength coefficient is a first questionable step, because the term $\left(2 \tau_{f}^{\prime} / \sigma_{f i}^{\prime}\right)^{2}$ reaches values between 0.17 and 15.4 for different materials within the FatLim data set. If the whole $b_{M}$ parameter is evaluated, it can be found that it spans between 0.0003 for the Sauer set ([60], present also in AMSD25 as SaL) and the value of 2014 in the Sanetra-Esderts set $([61,62]$, not present in AMSD25). This wide range of values that affect not only the effect of $N_{m}$ but also of $N_{a}$ could serve as a kind of warning. All parameters used to calculate $b_{M}$ are unaffected by the response of the material to the mean stress effect. The key question then is: Is any relation of the $b_{M}$ parameter to the potential influence of $N_{m}$ on the equivalent stress likely to be correct? 
The FAD003 case results in a moderate response in this case as its $b_{M}$ parameter reaches 68.7. The reason why the FAD003 evaluation is going wrong way (up to the negative term below the square root of Equation (18)), is surprisingly linked to the exponent $g$ (Equation (18)), which changes wildly within FatLim set of materials from -1.38 to 1.75 . In the case of FAD003, this value is -0.81 , which means that the higher mean stress in the FAD003 load case causes the complete bracket multiplying the $N_{\max }$ term to fall below zero. In connection with the low shear stress amplitude in this load case, it leads to a negative output below the square root. The criterion cannot provide a real output to calculate the equivalent stress. It is important to note that this does not happen for a case with high compressive mean stresses, but vice versa for a case of high tensile mean stress, which goes in a false direction due to factors unrelated to the mean stress effect.

If the $\{\mathrm{nMS}\}$ group is assessed to study the general behavior of the criterion without the problematic mean stress effect, a single non-conservative outlier can be found for a test case from Simbürger's data [63], which is well mastered by most other criteria (and thus it did not project into AMSD25). No other explanation for this output can be found than that it is again caused by the erratic behavior of the MDC criterion caused by the selection of $b_{M}$ and $g$ parameters, as commented in the previous paragraph. Even in this \{nMS\} case, though there is no mean stress, this effect remains active because $N_{\text {max }}$ reduces to $N_{a}$. Another outlier, this time on the conservative side up to $\triangle F I=70.9 \%$ can be found for the PSSB003 case, which is also in AMSD25. If these two outliers were removed, the range of $\triangle F I$ values would reduce to $36.3 \%$, which would be a nice value that many other criteria are not able to reach. However, the QCP criterion [10], which is also built as a combination of quadratic terms of shear and normal stress amplitudes, is for this $\{\mathrm{nMS}\}$ case reaching results which are less scattered. In this way it can be stated that the bracket with Basquin curve terms, which harmed the implementation of the mean stress effect, also negatively affects the $\{\mathrm{nMS}\}$ group of tests.

The reasonable well-substantiated comparison of the MDC criterion with other newer methods in Table 10 can be found in the statistics for the $\{M D C\}$ set. This test set is already much smaller in its scope than the original FatLim data set, which limits the universality of the evaluation in a certain way.

\subsection{Mertens Criterion MMMH and the Derived M3HW Formulation}

It was previously commented in this paper that the original formulation of the $\mathrm{MMMH}$ criterion (Equation (25)) from Mertens et al. [51] does not provide acceptable results due to inappropriately mastered mean stress effect. Its reformulated version $\mathrm{M} 3 \mathrm{HW}$ from Equation (26) will be documented here. It could be commented that this is unfair, e.g., to the MDC criterion, which also suffers from the inaccurate implementation of the mean stress effect. However, the concept of the MMMH criterion based on the calculation of two scalar stress parameters $\sigma_{e q, a, M M M H}$ and $\sigma_{e q, m, M M M H}$ provides input to the commonly solved question of the mean stress effect. The multitude of approaches designed to deal with it was commented, e.g., by [52,64], and the Walker formula is well documented to provide reasonably good solution, while also taking into account that the fatigue strength in repeated axial loading $s_{0}$, necessary for its computation via Equation (27), is available for all affected load cases within FatLim. The implementation of the mean stress effect in the MDC or KP criteria is much more complicated, and many ways to deal with it could be designed. Because of this, the authors of this paper did not dare to intervene in those cases.

It is reasonable to demonstrate the comparison of prediction quality of the MMMH and M3HW versions adequately. Some details on it can be found in Table 13, where the prediction results were analyzed on the $\{A x\}$ group derived from the entire FatLim data set. Both the most extreme points referred in Max. and Min. parameters for the MMMH criterion are contained within the AMSD25 data set. These are FAD003 (the minimum value in MMMH evaluation, $R=0.7$ ) and Ra1002 (the maximum, $R=0.5$ ), while these load cases do not produce the extreme results anymore in the M3HW variant. The mean stress effect incorporated in Equation (25) is based on the fatigue strength in repeated axial loading 
similarly to the Walker formula in Equation (27). Thanks to that both solutions achieve $\Delta F I=0 \%$ for this load case, but the response to the load cases with high mean stress is inappropriate in the original MMMH configuration. It is logical that this lack of precision to deal with the mean stress effect projects to other load cases, including multiaxial ones. This is the reason why Section 3 refers to results solely of the M3HW version, and not to the original MMMH criterion.

Table 13. Comparison of the $\mathrm{MMMH}$ and $\mathrm{M} 3 \mathrm{HW}$ versions of the $\mathrm{MMMH}$ criterion on the $\{\mathrm{Ax}\}$ group from the FatLim data set.

\begin{tabular}{ccccc}
\hline $\boldsymbol{\Delta} \boldsymbol{F I} \mathbf{( \% )}$ in $\{\mathbf{A x}\}$ & Max. & Min. & Aver. & SD \\
\hline MMMH & 245.3 & -990.5 & -27.8 & 200.7 \\
M3HW & 51.8 & -16.3 & 3.8 & 13.1 \\
\hline
\end{tabular}

The involvement of the Walker formula in the equivalent stress amplitude computation in the $\mathrm{M} 3 \mathrm{HW}$ criterion makes its result in the $\{\mathrm{Ax}\}$ group better than most of the newly compared criteria here, and even of many other older criteria of the two-parametric nature not calibrated to the material response to the $s_{0}$ case. Among the new methods, only the Böhme criterion shows a better performance, which coincides with the note by Papuga et al. [10], that the inclusion of the mean shear stress effect positively affects the predictive quality also within the $\{A x\}$ group. In the case of $\{\mathrm{To}\}$ group concerning the pure torsion cases, the M3HW criterion ranks behind the Böhme and WS criteria, which are both perfect for the $t_{0}$ case, and their general behavior within this group is closer to the experimental response.

It is interesting to note that $\mathrm{M} 3 \mathrm{HW}$ (or $\mathrm{MMMH}$ ) criterion reaches identical output as the Böhme criterion for the $\{\mathrm{IP}\}$ group of in-phase load cases. A very similar output to the Böhme criterion is delivered by $\mathrm{M} 3 \mathrm{HW}$ (and $\mathrm{MMMH}$ ) in the value of the standard deviation of $\triangle F I$ also for the $\{\mathrm{OOP}, \mathrm{nMS}\}$ data set group, but criteria based on $\mathrm{MMMH}$ have the mean fatigue index substantially shifted to the non-conservative prediction $(-17.8 \%)$. If the criterion were to provide better prediction quality comparable with other better performing criteria presented here, improving the response to the $\{\mathrm{OOP}, \mathrm{nMS}\}$ configuration should be focused on.

\subsection{Yankin Criterion}

The criterion is evaluated in two versions depending on the formula used for calculating the shear strength in the cases where it is missing. The output in Tables 5, 7,9 and 10 shows that the use of the factors proposed in [54] and here provided in Equation (33) generates better results in most cases than the use of simple application of the von Mises formula. Within the $\{A x\}$ group, the mean $\triangle F I$ value is closer to zero and the standard deviation of the DMW version is also slightly better than that of the VM variant. Therefore, the DMW variant will be commented on in the next description of the prediction accuracy trends.

Despite the fact that this is a four-parametric criterion, the mean stress effect is not derived from repeated loading cases, which projects into non-zero $\Delta F I$ values obtained for $s_{0}$ and $t_{0}$ cases, in some cases even quite close to the extreme value found for this criterion within the subset (Ra1033 load case available also in AMSD25, when evaluated within $\{$ To\} group).

The performance of the Yankin criterion within the $\{\mathrm{nMS}\}$ group is moderate compared to other newly analyzed methods. It could be rated as similar to the Dang Van criterion as regards the reached statistical parameters. If the subgroup $\{\mathrm{IP}, \mathrm{nMS}\}$ is assessed, this method is even the best one among all the criteria evaluated, with the sole exception of the PCN criterion. The criterion, however, suffers when evaluated on the $\{\mathrm{OOP}, \mathrm{nMS}\}$ subgroup from extremely non-conservative mean $\Delta F I$ value of $-14.3 \%$, close to the value obtained by the Dang Van criterion or the M3HW criterion treated above. 
This value is obtained when analyzing the second invariant of the stress tensor deviator by the method of the minimum circumscribed hyperball, which is commonly used in other analyses (see e.g., [39]). Papuga et al. recently showed in [42] that this family of criteria can benefit from using the scheme of the minimum circumscribed hyperellipsoid instead, which could move these unsafe prediction outputs typical in the \{OOP\} group closer to zero $\Delta F I$ if applied here. This option was checked together with the DMW setup, and it improved the prediction results to some extent. This improvement concerns, however, only the group $\{\mathrm{OOP}\}$ and the subgroups derived from it, so its overall effect on the entire data set is limited. Within the $\{\mathrm{OOP}, \mathrm{nMS}\}$ group, its application leads to the improvement of the mean $\Delta F I=-14.3 \%$ (minimum circumscribed hyperball) to the mean $\Delta F I=5.4 \%$. Although this value is at least conservative, the move so far away from zero can be found excessive. This option of the computation setup was not thus further analyzed.

If the $\{Y\}$ subgroup is evaluated in Table 10, the results of the Yankin criterion are second best among the newly assessed criteria after the Böhme criterion. The most important outliers and a space for improvement are not in the domain of out-of-phase tests, where the option mentioned above is open for discussion, but in the implementation of the mean stress effect. The chosen dependency on static strength parameters does not seem to bring its fruit as it was expected by the authors.

\subsection{Comparison of the Responses to FatLim and AMSD25 Data Sets}

One of the questions this paper should answer is whether the shortened AMSD25 data set is usable for a quick evaluation of new criteria, so that researchers could easily check if their new proposals are promising for further elaboration. To find out, several new quantities were computed from Table 10, and they are provided in Table 14. These are the reduction factors $R F_{\max }$ and $R F_{\text {min }}$ to evaluate if some particular outliers of the $\Delta F I$ maximums or minimums were filtered out during the reduction of FatLim to AMSD25, and to what extent it affected the maximum and minimum $\Delta F I$ values. These are relative parameters computed in this way:

$$
\begin{aligned}
R F_{\text {max }} & =\frac{\max _{\text {FatLim }} \Delta F I-\max _{\text {AMSD25 }} \Delta F I}{\max _{\text {FatLim }} \Delta F I} \\
R F_{\text {min }} & =\frac{\min _{\text {FatLim }} \Delta F I-\min _{\text {AMSD25 }} \Delta F I}{\min _{\text {FatLim }} \Delta F I}
\end{aligned}
$$

The third parameter $x S D$ describes the increase in the $\triangle F I$ standard deviation related to reducing FatLim to AMSD25. The increase is inevitable as the AMSD25 data set contains the data, which present the hardest nuts to crack for most criteria:

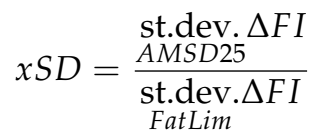

Table 14 shows that the reduction of the FatLim data set of 284 items to the smaller and more easily documented AMSD25 data set comprising 57 items is possible. It is true that some of the outliers for some of the criteria were lost in the reduction process, as can be seen by the RF factors, but the value of the standard deviation is the more descriptive and the more important parameter of the overall scatter, according to the authors. It can be observed that it worsened in this process by relatively narrow range of $x S D$ factor between 1.41 and 1.95. It could be thus expected that the standard deviation of $\triangle F I$ of some new criterion on AMSD25 could be projected to the estimated standard deviation of the entire FatLim data set if divided by a factor of 1.4. 
Table 14. Evaluation of the impact of the reduction in data set content from the FatLim set to the AMSD25 data set.

\begin{tabular}{|c|c|c|c|c|c|c|c|c|c|c|c|c|c|}
\hline \multirow{2}{*}{ Param } & \multirow{2}{*}{ PCN } & \multirow{2}{*}{ PIN } & \multirow{2}{*}{ MMP } & \multirow{2}{*}{ DV } & \multicolumn{3}{|c|}{ Khalij-Pagnacco } & \multirow{2}{*}{ WS } & \multirow{2}{*}{ Böhme } & \multirow{2}{*}{ MDC } & \multirow{2}{*}{ M3HW } & \multicolumn{2}{|c|}{ Yankin } \\
\hline & & & & & NK & OP & GOU & & & & & VM & DMW \\
\hline$R F_{\max }$ & $7.0 \%$ & $0.0 \%$ & $0.0 \%$ & $0.0 \%$ & $0.0 \%$ & $0.0 \%$ & $0.0 \%$ & $0.0 \%$ & $8.0 \%$ & $0.0 \%$ & $0.0 \%$ & $0.0 \%$ & $0.0 \%$ \\
\hline$R F_{\min }$ & $0.0 \%$ & $0.0 \%$ & $11.1 \%$ & $0.2 \%$ & $9.0 \%$ & $0.0 \%$ & $38.5 \%$ & $0.0 \%$ & $0.0 \%$ & $0.0 \%$ & $4.1 \%$ & $0.0 \%$ & $0.0 \%$ \\
\hline$x S D$ & 1.50 & 1.95 & 1.41 & 1.67 & 1.77 & 1.77 & 1.77 & 1.58 & 1.71 & 1.76 & 1.43 & 1.53 & 1.56 \\
\hline
\end{tabular}

This analysis can be completed by the check of the shift of the average $\Delta F I$ value due to the reduction. This value can change relatively wildly for the worst criteria, but their performance in other statistical parameters in Table 10 or Table 14 shows that something such as this can be expected. If the better performing criteria are assessed, this is within $5 \%$ in the absolute value. Even here, AMSD25 seems to promise quick and relatively precise estimates of the general properties of the new criteria. This value becomes much bigger in the case of KP and MDC criteria (and to some extent also in the case of the WS criterion), but these deviations are quite logical outcomes when the mean stress effect is not properly mastered, thus causing extreme dispersion of the fatigue index errors.

\section{Conclusions}

The paper reports on a comparison of six recently introduced multiaxial fatigue strength estimation criteria-the KP criterion by Khalij et al. [36], the WS criterion by Wang et al. [43], the Böhme criterion [46], the MDC criterion by Margetin et al. [48], the MMMH criterion by Mertens et al. [51], and the Yankin criterion [53]. To refer to their quality, the complete FatLim data set [32] and the abbreviated AMSD25 data set [31] were used for validation. To get some reference to previous attempts at such large-scale validation [26], four reference criteria were chosen - the PCN criterion [10], the PIN criterion [17], the MMP criterion [30], and the Dang Van criterion [33]. The following conclusions can be drawn:

1. Although none of the newly validated criteria delivered better prediction quality than the PCN (or PIN) criterion, the Böhme criterion is quite close to it. No other criterion provides a similarly precise output, mostly due to the implementation of the mean stress effect that fails.

2. The WS criterion based on a specific solution for critical plane determination does not provide any proof that its use in out-of-phase load cases brings any improvement in comparison to the maximum damage concept.

3. The MDC criterion establishes its mean stress effect based on the parameters of the Basquin curves in fully reversed axial loading and in fully reversed torsion. The results clearly manifest that this decision brings about an unreasonable scatter in prediction quality for cases including mean stresses.

4. The original MMMH criterion introduced by Mertens et al. [51] was modified to a new formulation $\mathrm{M} 3 \mathrm{HW}$, which binds the amplitude and mean stress components through the Walker formula. The original MMMH formula led to high aberrations when mastering the load cases with high mean stresses.

5. The application of the shorter AMSD25 data set for validation practice is promising, because the set allows to limit the scope of necessary calculations while preserving the most demanding load cases.

Author Contributions: Conceptualization, J.P.; methodology, J.P.; software, J.P., M.N., E.C. and L.S.; validation, J.P., M.N., E.C. and L.S.; formal analysis, J.P., M.N. and L.S.; investigation, J.P., M.N., E.C. and L.S.; resources, J.P. and A.H.; data curation, J.P., M.N. and L.S.; writing-original draft preparation, J.P., M.N. and L.S.; writing-review and editing, J.P., M.N., A.H., E.C. and L.S.; visualization, J.P.; supervision, J.P. and A.H.; project administration, J.P. and A.H.; funding acquisition, J.P. and A.H. All authors have read and agreed to the published version of the manuscript. 
Funding: This research was funded by the Grant Agency of the Czech Technical University in Prague, grant No. SGS20/158/OHK2/3T/12 (J.P., M.N. and E.C.) and by European Social Fund, grant “Mobility CTU—STA" CZ.02.2.69/0.0/0.0/18_053/0016980 (J.P.).

Institutional Review Board Statement: Not applicable.

Informed Consent Statement: Not applicable.

Data Availability Statement: Data concerning the AMSD25 data set and the computed fatigue index errors are contained within the article.

Acknowledgments: The kind help of Leila Khalij and Emmanuel Pagnacco in clarifying details of their criterion is appreciated.

Conflicts of Interest: The authors declare no conflict of interest. The funders had no role in the design of the study; in the collection, analyses, or interpretation of data; in the writing of the manuscript, or in the decision to publish the results.

\section{Abbreviations}

The following abbreviations are used in this manuscript:

AMSD25 dataset defined in [31]

DV Dang Van criterion [33]

DMW version of the shear strength estimation related to [54]

IP in-phase loading

KP Khalij-Pagnacco criterion [36]

LHS left-hand side of a formula

MDC Margetin-Ďurka-Chmelko criterion [48]

MMP Manson-McKnight-Papuga criterion [30]

MS load case including mean stress

MS- $\quad$ load case including negative mean stress

nMS load case without any mean stress involved

NP non-proportional loading

OOP out-of-phase loading

PCN Papuga PCN critical plane criterion [10]

PIN Papuga PIN integral criterion [17]

SD standard deviation

VM version of the shear strength estimation from von Mises formula

WS Wang-Shang criterion [43]

\section{Nomenclature}

$a, b, c, d, g \quad(-)$ material parameters of various multiaxial fatigue strength estimation methods

$b \quad(-)$ fatigue strength exponent in axial loading

$b_{t} \quad(-)$ fatigue strength exponent in torsion

C $(\mathrm{MPa})$ shear stress on an examined plane

$\delta \quad\left(^{\circ}\right)$ phase shift of the given stress signal

$\triangle F I \quad(\%)$ fatigue index error

FI (-) fatigue index

$\sqrt{ } J_{2} \quad(-)$ second invariant of the stress tensor deviator

$\kappa \quad(-)$ ratio of fatigue strengths in fully reversed loadings $\left(s_{-1} / t_{-1}\right)$

$N \quad(\mathrm{MPa})$ normal stress on an examined plane

$R_{e} \quad(\mathrm{MPa})$ yield stress

$R_{m} \quad$ (MPa) tensile strength

$R_{m t} \quad(\mathrm{MPa})$ shear strength

$s \quad(\mathrm{MPa})$ fatigue strength in axial loading

$\sigma \quad(\mathrm{MPa})$ nominal axial stress induced by axial loading

$s_{f}^{\prime} \quad(\mathrm{MPa})$ fatigue strength coefficient in axial loading 


\begin{tabular}{|c|c|}
\hline$s_{H}$ & (MPa) hydrostatic stress \\
\hline$t$ & (MPa) fatigue strength in torsion \\
\hline$\tau$ & (MPa) nominal shear stress induced by torsion \\
\hline$\tau_{f}^{\prime}$ & $(\mathrm{MPa})$ fatigue strength coefficient in torsion \\
\hline$\theta, \varphi$ & $\left({ }^{\circ}\right)$ Euler angles defining the orientation of the examined plane \\
\hline \multicolumn{2}{|c|}{ Indexes } \\
\hline 0 & related to repeated loading (from 0 to val, where val is the stress value) \\
\hline-1 & related to fully reversed loading (from -val to val, where val is the stress value) \\
\hline$a$ & amplitude \\
\hline$E q$ & equivalent \\
\hline$m$ & mean value \\
\hline $\max$ & maximum value \\
\hline$x, y, z$ & $\begin{array}{l}\text { cylindrical coordinate system, where } x \text { coincides with the sample axis, } y \text { is } \\
\text { tangential and } z \text { radial }\end{array}$ \\
\hline
\end{tabular}

\section{References}

1. Gough, H.J.; Pollard, H.V. The Strength of Metals under Combined Alternating Stresses. Proc. Inst. Mech. Eng. 1935, 131, 3-103. [CrossRef]

2. Gough, H.J.; Pollard, H.V. Properties of Some Materials for Cast Crankshafts, with Special Reference to Combined Stresses. Proc. Inst. Automob. Eng. 1936, 31, 821-893. [CrossRef]

3. Gough, H.J. Engineering Steels under Combined Cyclic and Static Stresses. Proc. Inst. Mech. Eng. 1949, 160, 417-440. [CrossRef]

4. Findley, W.N.; Coleman, J.J.; Hanley, B.C. Theory for Combined Bending and Torsion Fatigue Data for SAE 4340 Steel. In Technical Report No. 1 on Basic Research on Fatigue Failures under Combined Stress; Brown University: Providence, RI, USA, 1956.

5. Findley, W.N. Combined-Stress Fatigue Strength of 76S-T61 Aluminum Alloy with Superimposed Mean Stresses and Corrections for Yielding; National Advisory Committee for Aeronautics: Washington, DC, USA, 1953.

6. Rotvel, F. Biaxial Fatigue Tests with Zero Mean Stresses Using Tubular Specimens. Int. J. Mech. Sci. 1970, 12, 597-613. [CrossRef]

7. Mielke, S. Festigkeitsverhalten Metallischer Werkstoffe unter Zweiachsiger Schwingender Beanspruchung mit Verschiedenen Spannungszeitverläufen. Ph.D. Thesis, RWTH Aachen, Aachen, Germany, 1980.

8. Fatemi, A.; Socie, D.F. A Critical Plane Approach to Multiaxial Fatigue Damage Including Out-of-Phase Loading. Fatigue Fract. Eng. Mater. Struct. 1988, 11, 149-165. [CrossRef]

9. Ninic, D.; Stark, H.L. A Multiaxial Fatigue Damage Function. Int. J. Fatigue 2007, 29, 533-548. [CrossRef]

10. Papuga, J.; Halama, R. Mean Stress Effect in Multiaxial Fatigue Limit Criteria. Arch. Appl. Mech. 2019, 89, 823-834. [CrossRef]

11. Matake, T. An Explanation on Fatigue Limit under Combined Stress. Bull. JSME 1977, 20, 257-263. [CrossRef]

12. McDiarmid, D. Mean Stress Effects in Biaxial Fatigue Where the Stresses Are Out-of-Phase and Different Frequencies. In Fatigue under Biaxial/Multiaxial Loading; ESIS: Rome, Italy, 1991; pp. 321-335.

13. Susmel, L.; Tovo, R.; Lazzarin, P. The Mean Stress Effect on the High-Cycle Fatigue Strength from a Multiaxial Fatigue Point of View. Int. J. Fatigue 2005, 27, 928-943. [CrossRef]

14. Liu, J.; Zenner, H. Berechnung Der Dauerschwingfestigkeit Bei Mehrachsiger Beanspruchung-Teil 1. Mater. Und Werkst. 1993, 24, 240-249. [CrossRef]

15. Papadopoulos, I.V. A New Criterion of Fatigue Strength for Out-of-Phase Bending and Torsion of Hard Metals. Int. J. Fatigue 1994, 16, 377-384. [CrossRef]

16. Kenmeugne, J.L.; Vidal-Salle, E.; Robert, J.L.; Bahuaud, R.J. On a New Multiaxial Fatigue Criterion Based on a Selective Integration Approach. In Fatigue '96: Proceedings of the 6th International Fatigue Congress; Elsevier: Amsterdam, The Netherlands, 1996; pp. 1013-1018.

17. Papuga, J.; Suchý, L.; Růžička, M. Mean Shear Stress Effect Built into the Multiaxial Fatigue Strength Estimation Method of an Integral Type. In MATEC Web of Conferences; EDP Sciences: Les Ulis, France, 2019; Volume 300. [CrossRef]

18. Crossland, B. Effect of Large Hydrostatic Pressure on the Torsional Fatigue Strength of an Alloy Steel. In Proceedings of the Proc International Conference on Fatigue of Metals, London, UK, 10-14 September 1956; Institution of Mechanical Engineers: London, UK, 1956; pp. 138-149.

19. Sines, G. Behavior of Metals under Complex Static and Alternating Stresses. In Metal Fatigue; Sines, G., Waisman, L., Eds.; McGraw-Hill: New York, NY, USA, 1959; pp. 145-169.

20. Kakuno, H.; Kawada, Y. A New Criterion of Fatigue Strength of a Round Bar Subjected to Combined Static and Repeated Bending and Torsion. Fatigue Fract. Eng. Mater. Struct. 1979, 2, 229-236. [CrossRef]

21. Stefanov, S.H. The Curvilinear Integral Method: Testing 2 (under Non-Proportional Pulsating Axial Force and Internal Pressure). Int. J. Fatigue 1996, 18, 41-48. [CrossRef]

22. Weber, B. Fatigue Multiaxiale des Structures Industrielles Sous Chargement Quelconque. Ph.D. Thesis, INSA, Lyon, France, 1999.

23. Susmel, L. Multiaxial Notch Fatigue; Woodhead Publishing: Sawston, UK, 2009; ISBN 9781439803011. 
24. Papuga, J.; Růžička, M. Two New Multiaxial Criteria for High Cycle Fatigue Computation. Int. J. Fatigue 2008, $30,58-66$. [CrossRef]

25. Papuga, J. Fatlim Selector. Available online: http://www.pragtic.com/experiments.php (accessed on 15 August 2020).

26. Papuga, J. A Survey on Evaluating the Fatigue Limit under Multiaxial Loading. Int. J. Fatigue 2011, 33, 153-165. [CrossRef]

27. Susmel, L. Comments on "A Survey on Evaluating the Fatigue Limit under Multiaxial Loading" by Jan Papuga. Int. J. Fatigue 2011, 33, 1392-1395. [CrossRef]

28. Papuga, J. Answer to Comments on "A Survey on Evaluating the Fatigue Limit under Multiaxial Loading". Int. J. Fatigue 2011, 33, 1396-1402. [CrossRef]

29. Bruun, Ø.A.; Härkegård, G. A Comparative Study of Design Code Criteria for Prediction of the Fatigue Limit under In-Phase and out-of-Phase Tension-Torsion Cycles. Int. J. Fatigue 2015, 73, 1-16. [CrossRef]

30. Papuga, J.; Fojtík, F. Multiaxial Fatigue Strength of Common Structural Steel and the Response of Some Estimation Methods. Int. J. Fatigue 2017, 104, 27-42. [CrossRef]

31. Papuga, J.; Vízková, I.; Nesládek, M.; Trubelová, Š. Validation Data Set for Testing the Criteria for Multiaxial Fatigue Strength Estimation. Fatigue Fract. Eng. Mater. Struct. 2018, 41, 2259-2271. [CrossRef]

32. Papuga, J.; Kal'avský, A.; Lutovinov, M.; Vízková, I.; Parma, S.; Nesládek, M. Evaluation of Data Sets Usable for Validating Multiaxial Fatigue Strength Criteria. Int. J. Fatigue 2021, 145, 106093. [CrossRef]

33. Dang Van, K. Sur La Résistance à La Fatigue Des Métaux. Sci. Techniq. L'Armement 1973, 47, 647.

34. Papuga, J.; Healey, R.A. Who Should Bear Responsibility? Benchmarks in Fatigue Prediction. Bull. ČSM 2019, $2019,18-42$.

35. Fojtík, F.; Papuga, J. Issues Encountered in the Application of Multiaxial Fatigue Strength Methods to Experiments with Various Stress Distributions. Int. J. Fatigue 2021, 149, 106295. [CrossRef]

36. Khalij, L.; Pagnacco, E.; Troian, R. Fatigue Criterion Improvement of Gough and Nishihara \& Kawamoto to Predict the Fatigue Damage of a Wide Range of Metallic Materials. Int. J. Fatigue 2017, 99, 137-150. [CrossRef]

37. Liu, J. Weakest Link Theory and Multiaxial Criteria. In European Structural Integrity Society; Elsevier: Amsterdam, The Netherlands, 1999; pp. 55-68.

38. Nishihara, T.; Kawamoto, M. The Strength of Metals under Combined Alternating Bending and Torsion with Phase Difference. In Memories of the College of Engineering; Kyoto Imperial University: Kyoto, Japan, 1945; Volume 11, pp. 85-112.

39. Papadopoulos, I.V.; Davoli, P.; Gorla, C.; Filippini, M.; Bernasconi, A. A Comparative Study of Multiaxial High-Cycle Fatigue Criteria for Metals. Int. J. Fatigue 1997, 19, 219-235. [CrossRef]

40. Sonsino, C.M. Influence of Material's Ductility and Local Deformation Mode on Multiaxial Fatigue Response. Int. J. Fatigue 2011, 33, 930-947. [CrossRef]

41. Papuga, J.; Nesládek, M.; Jurenka, J. Differences in the Response to In-Phase and out-of-Phase Multiaxial High-Cycle Fatigue Loading. Frat. Integrità Strutt. 2019, 13, 163-183. [CrossRef]

42. Papuga, J.; Cízová, E.; Karolczuk, A. Validating the Methods to Process the Stress Path in Multiaxial High-Cycle Fatigue Criteria. Materials 2021, 14, 206. [CrossRef]

43. Wang, X.-W.; Shang, D.-G.; Sun, Y.-J.; Chen, H. Multiaxial High-Cycle Fatigue Life Prediction Model Considering Mean Shear Stress Effect under Constant and Variable Amplitude Loading. Theor. Appl. Fract. Mech. 2018, 96, 676-687. [CrossRef]

44. Bannantine, J.A.; Socie, D.F. A Multiaxial Fatigue Life Estimation Technique. In Advances in Fatigue Lifetime Predictive Techniques; Mitchell, M.R., Landgraf, R.W., Eds.; ASTM International: Philadelphia, PA, USA, 1992; pp. 249-275.

45. Carpinteri, A.; Macha, E.; Brighenti, R.; Spagnoli, A. Expected Principal Stress Directions under Multiaxial Random Loading. Part I: Theoretical Aspects of the Weight Function Method. Int. J. Fatigue 1999, 21, 83-88. [CrossRef]

46. Böhme, S.A.; Vinogradov, A.; Papuga, J.; Berto, F. A Novel Predictive Model for Multiaxial Fatigue in Carburized Bevel Gears. Fatigue Fract. Eng. Mater. Struct. 2021, 44, 2033-2053. [CrossRef]

47. Zenner, H.; Simbürger, A.; Liu, J. On the Fatigue Limit of Ductile Metals under Complex Multiaxial Loading. Int. J. Fatigue 2000, 22, 137-145. [CrossRef]

48. Chmelko, V.; Margetin, M. The Performance of Selected Multiaxial Criteria under Tension/Torsion Loading Conditions. Int. J. Fatigue 2020, 135, 105532. [CrossRef]

49. Mertens, H.; Liebich, R. A Time Dependent Equivalent Stress Function for Proportional and Non-Proportional Transient Loaded and Notched Metallic Components. Int. J. Fatigue 2017, 103, 294-308. [CrossRef]

50. Mertens, H.; Pucknat, D.; Zeise, B. Allgemeine Vergleichsspannungshypothese zur Lebensdauerberechnung metallischer Bauteile/Universal Equivalent Stress Hypothesis for Fatigue Calculations of Metal Components. Konstruktion 2017, 69, 78-82. [CrossRef]

51. Mertens, H.; Kamieth, R.; Liebich, R. Fatigue Calculation for Transient Proportional and Non-Proportional Multiaxial Vibrational Stress for Component Optimisation Based on the Modified Mohr-Mises-Hypothesis. Int. J. Fatigue 2020, 137, 105643. [CrossRef]

52. Papuga, J.; Vízková, I.; Lutovinov, M.; Nesládek, M. Mean Stress Effect in Stress-Life Fatigue Prediction Re-Evaluated. In MATEC Web Conferences; EDP Sciences: Les Ulis, France, 2018; Volume 165. [CrossRef]

53. Yankin, A.; Mugatarov, A.I.; Wildemann, V.E. Influence of Different Loading Paths on the Multiaxial Fatigue Behavior of 2024 Aluminum Alloy under the Same Amplitude Values of the Second Invariant of the Stress Deviator Tensor. Frat. Ed Integrità Strutt. 2020, 15, 327-335. [CrossRef] 
54. Deutschman, A.D.; Michels, C.E.; Wilson, C.E. Machine Design: Theory and Practice, 1st ed.; Collier-Macmillan International: New York, NY, USA, 1975.

55. Liu, J. Beitrag Zur Verbesserund Der Dauerfestigkeitsberechnung Bei Mehrachsiger Beanspruchung. Ph.D. Thesis, Universität Clausthal, Clausthal, Germany, 1991.

56. Rausch, T. Zum Schwingfestigkeitsverhalten von Gusseisenwerkstoffen unter einachsiger und mehrachsiger Beanspruchung am Beispiel von EN-GJV-450. Ph.D. Thesis, Shaker Verlag, Aachen, Germany, 2011.

57. Cengiz, C. Out of Phase Multiaxial Fatigue Strength of a Cast Iron. Master's Thesis, Politecnico di Milano, Milan, Italy, 2012.

58. Heidenreich, R. Schubspannungsintensitätshypothese-Dauerschwingfestigkeit Bei Mehrachsiger Beanspruchung; FKM: Frankfurt, Germany, 1983; Volume 105.

59. Carpinteri, A.; Spagnoli, A. Multiaxial High-Cycle Fatigue Criterion for Hard Metals. Int. J. Fatigue 2001, 23, 135-145. [CrossRef]

60. Sauer, J.A.; Lemmon, D.C. Effect of Steady Stress on Fatigue Behavior of Aluminum. Trans. Am. Soc. Met. 1950, 42, 559-576.

61. Sanetra, C. Untersuchungen zum Festigkeitsverhalten bei mehrachsiger Randombeanspruchung unter Biegung und Torsion; Technische Universität Clausthal: Clausthal, Germany, 1991.

62. Esderts, A. Betriebsfestigkeit bei mehrachsiger Biege- und Torsionsbeanspruchung. Ph.D. Thesis, Technische Universität Clausthal, Clausthal, Germany, 1995.

63. Simbürger, A. Festigkeitsverhalten Zäher Werkstoffe bei einer Mehrachsigen Phaseverschobenen Schwingbeanspruchung mit Körperfesten und Veränderlichen Hauptspannungsrichtungen. Ph.D. Thesis, TH Darmstadt, Darmstadt, Germany, 1975.

64. Dowling, N.E.; Calhoun, C.A.; Arcari, A. Mean Stress Effects in Stress-Life Fatigue and the Walker Equation. Fatigue Fract. Eng. Mater. Struct. 2009, 32, 163-179. [CrossRef] 